\title{
Biogeochemical extremes and compound events in the ocean
}

\section{Journal Article}

Author(s):

Gruber, Nicolas (1); Boyd, Philip W.; Frölicher, Thomas L.; Vogt, Meike

Publication date:

2021-12-16

Permanent link:

https://doi.org/10.3929/ethz-b-000521508

Rights / license:

In Copyright - Non-Commercial Use Permitted

\section{Originally published in:}

Nature 600(7889), https://doi.org/10.1038/s41586-021-03981-7

\section{Funding acknowledgement:}

175787 - X-EBUS: Extreme Ocean Weather Events and their Role for Ocean Biogeochemistry and Ecosystems in Eastern Boundary Upwelling Systems (SNF)

820989 - Our common future ocean - quantifying coupled cycles of carbon, oxygen, and nutrients for determining and achieving safe operating spaces with respect to tipping points $(E C)$ 


\title{
Nature Perspectives
}

\section{OCEAN BIOGEOCHEMICAL EXTREMES AND COMPOUND EVENTS}

\author{
Nicolas Gruber ${ }^{1, *}$, Philip W. Boyd ${ }^{2}$, Thomas L. Frölicher ${ }^{3,4}$, and Meike Vogt ${ }^{1}$ \\ ${ }^{l}$ Environmental Physics, Institute of Biogeochemistry and Pollutant Dynamics, ETH Zürich, Zürich, Switzerland. \\ * corresponding author: nicolas.gruber@env.ethz.ch \\ ${ }^{2}$ Institute for Marine and Antarctic Studies, University of Tasmania, Hobart, Tasmania, Australia \\ ${ }^{3}$ Climate and Environmental Physics, University of Bern, Bern, Switzerland \\ ${ }^{4}$ Oeschger Centre for Climate Change Research, University of Bern, Bern, Switzerland
}

This is the preprint version of August 12, 2021.

It differs from the final published version with respect to some editorial changes (e.g., no

references in the abstract) and some changes in nomenclature (e.g., high acidity extremes were

changed to ocean acidity extremes), but otherwise it is an accurate reflection of the final published version.

Nicolas Gruber, December 15, 2021.

The published version is available through https://www.nature.com/articles/s41586-021-03981-7 
$1^{\text {st }}$ paragraph

The ocean is warming, losing oxygen, and it is being acidified, primarily as a result of anthropogenic carbon emissions ${ }^{1-4}$. With ocean warming, acidification, and deoxygenation projected to increase for decades $^{5,6}$, extreme events, such as marine heatwaves ${ }^{7}$, are likely to intensify, occur more often, persist for longer, and extend over larger regions ${ }^{8-11}$. Nevertheless, our understanding of oceanic extreme events, associated with warming, low oxygen concentrations or high acidity, and their impacts on marine ecosystems remains limited $^{7,10,12-15}$. Of particular concern are compound events, multiple extreme events that occur simultaneously or in close sequence, because their individual effects may interact synergistically ${ }^{16}$. Here we assess patterns and trends in open ocean extremes based on the existing literature and global and regional model simulations. Furthermore, we discuss the potential impacts of individual and compound extremes on marine organisms and ecosystems. We propose a pathway towards an improved understanding of extreme events and the capacity of marine life to respond to them. The absolute conditions exhibited by today's extreme events may be a harbinger of what may become "normal" in the future ${ }^{10}$. In consequence, pursuing this research effort may also help better understand the responses of marine organisms and ecosystems to future climate change. (200 words)

MAIN

The direct and indirect impact of human -driven emissions of $\mathrm{CO}_{2}$ on marine systems are pervasive (Fig. 1). By burning fossil fuels and altering land-use, human activities have increased atmospheric $\mathrm{CO}_{2}$ by $\sim 50 \%$ in the last $200 \mathrm{yrs}^{17}$. The resulting change in the Earth's radiative balance generates excess heat, more than $90 \%$ of which is taken up by the ocean, thereby warming $i t^{4}$. This ocean warming leads to a loss of dissolved oxygen, i.e., deoxygenation ${ }^{18}$, through the reduction of the solubility of dissolved oxygen. This loss is greatly amplified by the warming-induced changes in upper ocean stratification and ventilation ${ }^{19,20}$ which tend to reduce the supply of oxygen from the surface ocean into the interior, where oxygen is continuously consumed through respiration and remineralization processes ${ }^{21}$. Furthermore, the rise in atmospheric $\mathrm{CO}_{2}$ also drives a strong flux of additional, i.e., anthropogenic, $\mathrm{CO}_{2}$ into the ocean ${ }^{22}$, leading to a reduction in the oceanic $\mathrm{pH}$ and in the saturation state, $\Omega$, of seawater with regard to mineral $\mathrm{CaCO}_{3}$, while the concentration of the hydrogen ion $\left[\mathrm{H}^{+}\right]$(i.e., the acidity) increases (corresponding to a decrease in $\mathrm{pH}=-\log \left[\mathrm{H}^{+}\right]$). Such changes are often summarized as "ocean acidification" 23 . These chemical changes are known to substantially affect marine organisms ${ }^{24,25}$, especially those forming shells made from mineral 
$\mathrm{CaCO}_{3}$ such as oysters, crabs, and corals as the lower saturation state impairs their ability to calcify ${ }^{26}$. These three hazards, i.e., those associated with ocean warming, acidification and deoxygenation are likely to continue for the coming decades even under emission scenarios that incorporate stringent cuts in future greenhouse gas emissions ${ }^{2,5,6}$.

As changes in ocean temperature, oxygen, and acidity unfold, extreme conditions in these properties are bound to change disproportionately (Fig. 1) ${ }^{27}$. In the ocean, our knowledge about such extreme events, i.e., the normally rare occurrences when a system is far outside the norm, is relatively limited. This is especially the case when comparing this with the situation on land where extremes are known to severely impact humans and ecosystems ${ }^{28,29}$. Best studied are marine heatwaves, where knowledge has grown rapidly in recent years ${ }^{7-9,11,15,30,31}$. For example, between 1982 and 2016 the number of days with marine heatwaves, defined here as days when the seasurface temperature (SST) exceeds its local 99th percentile, has doubled ${ }^{8}$, even though humandriven global warming caused the ocean surface to warm "only" by $\sim 0.4^{\circ} \mathrm{C}$ over this period ${ }^{32}$. One of the most prominent heatwaves was the "Blob" in the Northeast Pacific that occurred between 2013 and 2015 with SST anomalies, relative to 2002-2012, of up to $6^{\circ} \mathrm{C}^{33}$. This event had severe consequences for marine life, ranging from massive die-offs of marine birds, higher mortality of sea lions, reduced stocks of many commercially valuable fish, to pronounced shifts in zooplankton community structure ${ }^{12,34-37}$. The trend toward more frequent marine heatwaves is projected to continue under global warming, with the ocean encountering 16-fold more marine heatwave days compared to preindustrial conditions under a global warming of $1.5^{\circ} \mathrm{C}^{8}$. For example, a marine heatwave at the scale of the "Blob" is projected to occur every 10 years under this level of global warming $^{38}$. Similar trends are expected for extreme events associated with ocean deoxygenation and ocean acidification, but so far, with few exceptions for ocean acidity ${ }^{13,14}$, little is known about these extremes in terms of their distribution, intensity, or duration, primarily owing to the lack of observations. This is a serious gap, especially when considering the pervasive effects that extremes in any of these hazards might have on marine productivity, ecosystem structure and function, ecosystem services, and ultimately for humankind (Fig. 1), as has been demonstrated for marine heatwaves ${ }^{12,37}$. The potential for substantial ecosystem impacts could be exacerbated by compound extreme events, i.e., extremes in different hazards occurring simultaneously or in close spatial/temporal sequence ${ }^{16,39-41}$, owing to their potential for mutually reinforcing, i.e., synergistic, effects between the hazards ${ }^{42}$. Extreme events can rapidly push marine ecosystems and their constituents beyond the limits of their resilience and hence impair their capability to acclimate or adapt, especially due to their abrupt nature. Thus, extremes and especially the newly emerging ones could have worse effects than those emanating from the slow decadal-scale progression of the mean 
state (e.g., warming, deoxygenation or acidification) in response to the human-driven climatic drivers (Fig. 1). Single and compound extremes could also trigger abrupt major reshuffling of community structure with potentially grave consequences for marine ecosystem services ${ }^{43}$.

Here, we examine and discuss marine heatwaves and the biogeochemical extremes characterized by low oxygen and high acidity using existing literature and new results from global and regional model simulations. We thereby focus on the open ocean, where the largest gaps in knowledge exist, and do not include an assessment of potential extremes associated with losses of oxygen in nearshore areas driven by eutrophication processes ${ }^{3,44}$. We assess the patterns and trends of these open ocean extremes including the underlying processes, with special emphasis on compound extremes. We then discuss the potential impacts of individual and compound extremes on marine organisms and ecosystems, recognizing that our understanding of these impacts is, beyond marine heatwaves, not yet well developed. In response, we propose a conceptual framework in order to guide much-needed discussions.

\section{DISTRIBUTION AND TRENDS}

Marine heatwaves, and biogeochemical extremes associated with low oxygen and high acidity occur everywhere in the ocean, with both commonalities and important distinctions between the three types of extremes. To illustrate these extremes in a consistent manner across the globe, we use results from an Earth system model ${ }^{45,46}$. This global model was run for both preindustrial conditions as well as for the historical period up to 2020 under prescribed radiative forcing ${ }^{14}$. To define the extremes, we use a relative threshold approach with a fixed baseline based on a preindustrial reference period (see Box 1). Specifically, we selected either the 1st (oxygen) or the 99th (temperature and $\left[\mathrm{H}^{+}\right]$) percentile of the daily mean model output as our relative threshold, using results from a 500-yr long preindustrial control simulation as the reference. The choice of a preindustrial reference period provides us with statistically robust characteristics given the more than 180,000 days to sample from. Using a modern reference period $(1982-2019)$ for the characteristics investigated here yields very comparable results, although with lower spatiotemporal coherence, owing to the much shorter reference period (see supplementary material for a comparison). Our choice is also consistent with the use of the preindustrial reference period to define the climate target in the Paris agreement ${ }^{47}$. We opted to use a fixed relative threshold for all properties in order to ensure consistency across the three hazards for the purpose of this illustration. This approach assumes that organisms and ecosystems are well adapted to the local conditions, but are limited in their capabilities to deal with the extreme conditions that they 
encounter episodically (see Box 1) ${ }^{16}$. An important implication of the choice of a fixed relative threshold is that the characteristics of the extremes are changing with time when the underlying distribution is changing, e.g., any trend in the variable of choice implies a trend in the extremes ${ }^{16}$. We fully acknowledge that other definitions, e.g., the use of an absolute threshold ${ }^{13}$, or a moving baseline ${ }^{7,14}$, might be better choices depending on the questions being addressed and the biological impacts being investigated (see Box 1 for a discussion).

The spatial patterns of the mean intensity of the simulated extremes are remarkably coherent across the three investigated types of extremes within each depth level (Fig. 2a,b). But the spatial distribution of mean intensities shifts considerably between the surface and $200 \mathrm{~m}$ depth, i.e., the upper thermocline. At the surface, the most intense extremes of all types tended to occur in the mid to high latitudes (Fig. 2a), whereas at $200 \mathrm{~m}$ depth, the hotspot for the most intense extremes are the tropics (Fig. 2b).

At the ocean surface, marine heatwaves tend to have their maximum intensity in the temperate and subpolar latitudes and in the eastern equatorial Pacific, with intensities exceeding $1{ }^{\circ} \mathrm{C}$ (Fig., 2a; note that the intensity refers to the annual maximal size of the peak over threshold, i.e., the associated SST anomalies or magnitudes are nearly everywhere at least $1{ }^{\circ} \mathrm{C}$ larger and can be as large as $6^{\circ} \mathrm{C}$ ), consistent with observations (see Supplementary Material). The surface ocean distribution of the intensity of the high acidity extremes is overall similar to that of the heatwaves (Fig. 2a), but with some notable differences. Most striking are the generally much higher intensities in the North Pacific relative to the North Atlantic.

At $200 \mathrm{~m}$ depth, the most intense heatwaves tend to occur in the tropics, especially in the Pacific, and along the boundaries of the subtropical gyres with mean intensities that are of the same order of magnitude compared to those at the surface (Fig. 2b). The strongest high acidity and low oxygen extremes also tend to occur in the tropics, although slightly displaced poleward relative to the heatwaves. In addition, rather strong high acidity extremes occur at $200 \mathrm{~m}$ depth in the North Pacific, and at very high southern latitudes.

In the global average, the simulated heatwaves and high acidity extremes at the surface last in the preindustrial only about 10 days (see Fig. S5). Observational analyses of modern heatwaves actually suggest that an even shorter duration, i.e., of the order of a few days ${ }^{8,9}$. This difference remains even if we analyze the model results using the same modern reference period (1982-2019) as the observations (Figs. S1 and S2), suggesting that this is a model bias. Similar biases toward too long lasting events has been identified across all models analyzed so far ${ }^{48}$, irrespective of resolution ${ }^{49}$. However, it is conceivable that the observed durations are skewed on the short side, 
owing to the presence of missing observations in the SST product that could lead to artefactual breaks in the heatwaves ${ }^{50}$. Accepting this potential shortcoming, the model suggests that in the regions characterized by high intensity extremes, both types of extremes can persist for much longer than the average event, i.e., nearly two months, with individual events continuing for multiple months (for marine heatwaves) to years (for high acidity extremes). At $200 \mathrm{~m}$ depth, all types of extremes, including the low oxygen ones, last longer compared to the surface (Fig. S5). In the global mean, they persist for about 40 days, but with large regional differences. The intense extreme events near the equator endure for a few days only, while those at the edges of the tropics and in the higher latitudes can persist for more than 200 days.

Between 1861 and 2020, the simulated number of heatwaves and biogeochemical extremes increased substantially, both at the surface and at depth (Fig. 2c,d). Given our definition, the number of extreme days in preindustrial times is 3.65. Compared to that reference, the number of days characterized by a heatwave increased more than 10 fold to more than 40 days per year at both surface $\left(\right.$ see also $^{8}$ ) and $200 \mathrm{~m}$ depth, and those with low oxygen extremes at $200 \mathrm{~m}$ depth have increased about 5 fold. For the high acidity events, the entire ocean at surface and at $200 \mathrm{~m}$ depth is approaching a state of near permanent extreme conditions relative to preindustrial conditions ${ }^{14}$. These strong trends in all three variables reflect the substantial amount of ocean warming, acidification, and loss of oxygen that have occurred over the $20^{\text {th }}$ century (Fig. 1). These trends make the extremes not only last longer, but also more intense $e^{8,14}$. The near-permanent extreme conditions for $\left[\mathrm{H}^{+}\right]$are a direct consequence of the major imprint of ocean acidification on the ocean's carbonate chemistry, which has shifted todays' range of variability to lie nearly completely outside the range in preindustrial times. In such cases, when a trend pushes a system toward near permanent extreme conditions, other approaches, such as categories ${ }^{51}$, a shifting baseline ${ }^{14}$, or an absolute threshold may be better suited to characterize changes in extreme event characteristics, as well as their biological impacts (see also Box 1).

\section{PROCESSES CAUSING EXTREMES}

These temporal modulations in extremes are closely linked to the processes that give rise to them (Fig. 3). In general, the most intense extremes in our three variables of interest occur in the regions where variability is highest. This is largely a consequence of the fact that regions with high variability have broader distributions, which implies stronger exceedances (intensities) given our definition of extremes on the basis of relative thresholds. Studies using both observations and models have shown that most marine heatwaves (at least those occurring at the surface) occur either 
by local atmosphere-ocean interactions and associated ocean processes, such as upwelling, or by a horizontal displacement of the large-scale sea-surface temperature gradient ${ }^{7,31}$ (Fig. 3a,b). The lateral displacement mechanism drives many of the heatwaves in the western boundary currents ${ }^{31}$ and those reported in the Southern Ocean, while atmosphere-ocean interactions and the associated ocean processes drive nearly all the tropical heatwaves as well as many of those in the temperate latitudes (e.g. those associated with El Niño ${ }^{52}$, the Pacific "Blob" ${ }^{35}$ or the "Blob2.0" that emerged in $2019^{53}$ ). Atmosphere-ocean interactions tend to cause warming through several processes, involving reduced cloudiness, decreased wind speeds reducing vertical mixing, shifting winds altering ocean circulation, and changes in sea-surface temperature altering the atmospheric conditions in return. Some of these processes occur at scales of less than a few tens of kilometers, and are thus not fully resolved by our global model simulations. For the high acidity extremes at the surface, the underlying drivers have not been well studied. Model studies suggest an important role for upwelling (equatorial Pacific and western boundaries of the continents ${ }^{13}$ ) as well as shifts in the rate of vertical mixing and their interplay with altered biological productivity (high latitudes, ${ }^{54}$ ) (Fig. 3c,d,e). Unusually strong upwelling can cause a high acidity extreme event through the surface exposure of deeper waters with high $\left[\mathrm{H}^{+}\right]$concentrations. Similarly, high vertical mixing tends to bring high acidity waters toward the surface, which, when not opposed by the $\left[\mathrm{H}^{+}\right]$ decreasing effect of elevated biological productivity or reduced temperature, can create a high acidity extreme.

Extreme events occurring at depth have not been analyzed systematically on a global scale, although the literature is expanding rapidly at regional levels ${ }^{55-57}$. The dynamics identified in these studies and in our simulations permit some attribution. For example, the model-simulated low oxygen extremes in the $10^{\circ}$ to $20^{\circ}$ latitudinal band (Figure $2 \mathrm{~b}$ ) are likely driven by the lateral movement of the sharp boundary between the ventilated (high oxygen) subtropical gyre and the unventilated (low oxygen) tropical waters. Such lateral displacements occur in models and observations on annual to decadal timescales and have been well studied in the eastern tropical Pacific (see e.g. ${ }^{58}$ ). In the higher latitudes, the modeled low oxygen extremes at $200 \mathrm{~m}$ depth tend to be more patchy, with some of these associated with the (partially resolved) eddies in the model (Fig. 3f). Based on full eddy-resolving simulations ${ }^{59}$ as well as observations ${ }^{60}$, we expect that eddies and other mesoscale processes give rise to more of these smaller-scale extremes than simulated by the relatively coarse-resolution model employed here.

Many of the identified mechanisms can lead to more than just one type of extreme, potentially causing dual or triple compound events (Fig. 3). In particular, low oxygen and high 
acidity extreme events can be expected to co-occur frequently, since subsurface remineralization of organic matter simultaneously depletes oxygen and increases acidity ${ }^{61}$ (Fig. 3e). Similar cooccurrence can be expected in association with the lateral or vertical displacement of fronts, upwelling, thermocline heaving, and eddies, as all of these act on strongly anticorrelated gradients of oxygen and acidity (Fig. 3b,c,d,e,f). Under specific circumstances, e.g., during an atmospherically-forced heatwave, shifts of lateral gradients, upwelling, and thermocline heaving can cause even triple compound extremes, i.e., heatwaves co-occurring with low oxygen and high acidity extremes.

\section{OCEAN EXTREMES IN FOUR DIMENSIONS}

To date, most literature on ocean extremes has focused on the surface ocean only, even though extremes may occur anywhere in the water column. In addition, most prior studies, including our own analyses shown above, employed a Eulerian view, i.e., they focus on the evolution and properties of extremes at a fixed location. But ocean extremes often move laterally over many hundreds of kilometers during their lifetime, requiring a Lagrangian (i.e., a feature-following) perspective to fully capture their impact. For example, mesoscale eddies (Fig. 3f) have been observed to travel $>1000$ kilometers during their often multi-year lifetimes ${ }^{62,63}$. Thus, any pelagic organisms trapped within such an eddy, especially free-drifting organisms (plankton), will be exposed to the (potentially extreme) conditions associated with it for much longer compared to e.g., a benthic organism that resides in one place, encountering the extreme only in passing, i.e., in a Eulerian manner ${ }^{60,64}$. Moreover, in order to understand the impact and consequences of ocean extremes on marine organisms, ecosystems, and biogeochemistry, one needs to give special attention to their vertical extent, i.e., take the four-dimensional (space-time) nature of the extremes in full consideration. Changes in the depth stratum are very important for the occurrence of habitat compression, i.e., the squeezing of a suitable habitat into a much smaller volume owing to the presence of an extreme anywhere in the water column $n^{65,66}$.

To illustrate the four-dimensional nature of extremes, we use the example of the 2013-2015 "Blob" heatwave in the Northeast Pacific ${ }^{34,67,68}$. Observations revealed that this event unfolded in a complex manner in space and time, with the first exceptionally warm conditions emerging in late 2013 in the central northwestern Pacific, but moving subsequently toward the North American Coast and then offshore before ending in late 2015. The "Blob" heatwave appears to have had its maximum warming near the surface, but the extremely elevated temperatures extended to depths beyond $100 \mathrm{~m}$, although not uniformly so ${ }^{57,67}$. Analyses of Argo profiling float data revealed that 
the warming occurred at depth several months later, and subsequently propagated toward the North American continent with a lag relative to the anomalies at the surface of at least one year ${ }^{56}$. Indeed, the deep-water temperature anomalies associated with the "Blob" appear to have persisted for at least two additional years, being conspicuous into 2018 along most of the North American western seaboard ${ }^{56}$.

To investigate the Northeast Pacific 2013-15 "Blob" heatwave further, we use results from a hindcast simulation with a high resolution regional ocean biogeochemical model of the eastern Pacific [updated from ${ }^{69}$ ]. The model successfully simulates the observed evolution of the "Blob" heatwave (Figs. S3 and S4), revealing the spatio-temporal progression of the marine heatwave (Fig. 4a,b). Indeed, Fig 4b shows clearly how throughout the event a substantial part (up to 50\%) of the upper $100 \mathrm{~m}$ within the "Blob" encountered extremely high temperatures. This would be expected to force motile organisms that are sensitive to warming to greater depth, where temperatures are generally cooler. Similar habitat compressions can also occur laterally, i.e., by reducing the amount of cold-water habitat along the west Coast of the Americas ${ }^{66}$. The model simulation also reveals that the "Blob" was not only an extreme event with respect to high temperatures, but also with regard to high acidity and low oxygen (Fig 4a,c\&d). Both conditions extended to depth, potentially leading to a strong compounding habitat compression.

\section{COMPOUND EXTREMES}

Such dual or even triple compound extremes are of particularly high biological and/or ecological concern, especially when the hazards act synergistically ${ }^{42}$, as is the case, e.g., for oxygen and temperature $\mathrm{t}^{70-72}$ or $\mathrm{pH}$ and oxygen ${ }^{73}$.

The regional model simulations for the 2013-2015 "Blob" event provide a window to explore the nature of such compound extremes (Fig. 4a,c\&d). For example, the model simulations suggest that while high acidity and low oxygen dual extremes have occurred throughout the 1987 to 2016 period, the area affected by such dual extremes increased during the "Blob" more than tenfold (Fig. 4a). Critically, the "Blob" is associated with the first occurrences of dual events involving high acidity conditions, and especially four episodes where all hazards are extreme, i.e., a triple (heatwave/low oxygen/high acidity) compound event. The strongest such triple event occurred at the peak of the "Blob" in July 2015 , when nearly $25 \%$ of the eastern North Pacific $\left(20^{\circ} \mathrm{N}-60^{\circ} \mathrm{N}\right.$, $115^{\circ} \mathrm{W}-155^{\circ} \mathrm{W}$ ) was under heatwave conditions. The regional model simulates this triple event to occur offshore of the Northwest American Coast with many surrounding regions encountering the co-occurrence of at least two extreme conditions within the upper water column (Fig. 4c). The 
average profile of the simulated conditions for July 2015 within the central northeastern Pacific (white box in Fig. 4b) reveals that this triple event extended from the surface to nearly $100 \mathrm{~m}$, and that temperatures and acidity remained extremely high down to $\sim 150 \mathrm{~m}$ (Fig. $4 \mathrm{~d}$ ).

Thus, the model simulations suggest that the "Blob" event was more than just a strong and persistent heatwave, it was a compound extreme event. It remains to be determined in what way these compound extreme characteristics of the "Blob" may have contributed to the myriad of observed biological impacts ${ }^{34}$. Given the long-term trends in ocean warming, deoxygenation, and ocean acidification, such compound events defined on the basis of fixed baselines are bound to increase in number, intensity, and duration (Fig. 2c\&d).

\section{IMPACT ON ORGANISMS AND ECOSYSTEMS}

The well documented responses of marine life to individual extremes ${ }^{15,34}$ have raised awareness of the threats posed by such events ${ }^{12}$. Yet, our ability to translate these individual events into a generic causal framework to assess the impacts of extremes is currently very limited. This reflects our relatively poor understanding of the ramifications of extremes for marine life, especially when compared to terrestrial systems (e.g. ${ }^{74}$ ). Best understood are the impacts of marine heatwaves, i.e., the thermal stress they impose on marine organisms ${ }^{12,75}$, and especially on warm water corals ${ }^{76-78}$. In comparison, much less is known about the potential impact of low oxygen and high acidity extremes, with the exception of organisms living in coastal and nearshore habitats ${ }^{79-82}$. Least understood in terms of biological impacts are the potential synergistic effects that can amplify hazards during compound extremes ${ }^{78,83-85}$.

Even though our current knowledge about the biological impact of extremes is low, it is accumulating rapidly, with most coming from post-hoc analyses of time-series sites or impacted regions ${ }^{15,34,36,66,86-92}$ and increasingly from targeted lab and field-based experiments ${ }^{82-84,93,94}$. The insight emerging from this growing body of work is that extremes represent a complex and multifaceted threat to marine life (Boxes 1 and 2) that differs from that associated with the slow changes, decade by decade, by the stressors associated with climate change and increasing atmospheric $\mathrm{CO}_{2}$ 95,96. This is because when confronted with an extreme, organisms and ecosystems encounter additional challenges due to their exposure to the diverse characteristics of extremes ranging from abruptness, to magnitude, to heterogeneity along with the possibility of rapid recurrence (Box 2). Still, this does not imply we cannot learn from the large body of research conducted on the biological impact of the slowly-evolving hazards associated with ongoing ocean warming, acidification and deoxygenation and their interplay (e.g. ${ }^{97-101}$ ). However, careful thought will be 
required as to how best to apply these potentially informative datasets since their focus has been almost exclusively on biological responses to the magnitude of the hazard. At the same time, we have to recognize that not all extreme conditions will have a biological consequence. This is especially true for our statistical definition of extremes, i.e., our choice of a relative threshold approach. This caveat is perhaps most important for the high acidity and low oxygen extremes, but is also relevant for heatwaves.

In order to structure our understanding of the biological impact of extremes, we propose a framework spanned by two axes, i.e., the level of biological organisation and the timescale of the biological response to the key characteristics of extremes (Fig. 5). For the biological organisation, we commence with molecular and physiological responses within an individual cell (top), and extend this analysis up to the level of organisms and populations, and to ecosystems (bottom). For timescales, responses can occur from hours (left) to years and longer (right).

In the short-term, the impact of extremes, provided their absolute tolerance is not exceeded, depends critically on the plasticity of the organisms, i.e., physiological mechanisms that permit individual organisms to acclimatize in order to cope with environmental stress (Fig. 5). Also critical is the speed at which an organism can trigger these mechanisms relative to the abruptness of the event. For example, the activation of heat shock proteins (HSPs) ${ }^{102}$ is a common cellular-level response to the rapid onset of marine heatwaves ${ }^{103}$. But this strategy has its physiological limits, such as that imposed by the level of temperature-dependent oxidative stress on DNA ${ }^{102}$, leading to some of the most detrimental effects of extremes on marine life ${ }^{104}$.

On timescales of days to weeks, these intracellular acclimatization responses are associated with substantial costs ${ }^{83,102}$. They affect the fitness of the organism with respect to its behaviour, growth and reproduction. Organisms could overcome this disadvantage via adaptation ${ }^{105-107}$, but the compressed timescales of extreme events, in conjunction with their high intensity, imposes strong limits on this strategy. An exception might be persistent and/or recurrent extremes, as they provide the near constancy of elevated temperatures that permitted coccolithophores to adapt to elevated temperatures in a one year long lab-based incubation experiment ${ }^{107}$. Yet, in diatoms, adaptation to thermal stress has been shown to be limited under coincident nutrient stress due to physiological trade-offs ${ }^{108}$. For longer lived organisms that cannot adapt so rapidly, including many marine metazoan ectotherms ${ }^{109-111}$, enforced movement to cooler waters ${ }^{112,113}$ is a viable alternative strategy ${ }^{114}$, although it may come with additional costs for rates of growth and/or reproduction $^{83}$. Such lateral migrations have been well documented for marine heatwaves for 
several taxa $\mathrm{a}^{37,88,112}$. Often, the associated range changes cause a reshuffling of the species composition of the ecosystem. This can lead to increased competition among resident species ${ }^{115}$ and also may influence food web characteristics such as succession, functional diversity and redundancy ${ }^{116}$.

On time scales of months to years or more, ecosystems and their constituents may respond to extremes through various resilience mechanisms, including their capacity to resist change (resistance), to recover from damage, and to adapt to increasingly extreme environments ${ }^{117}$. Microevolutionary adaptation might actually be accelerated in response to extremes, especially in systems where an initial high genetic variability was substantially reduced owing to an extreme induced mass mortality ${ }^{118}$. At the level of entire ecosystems, compensatory dynamical processes $^{119}$, such as the substitution of affected species with others of similar function in diverse or functionally redundant ecosystems are successful strategies to conserve biomass, productivity, ecosystem structure and/or function in the presence of perturbations. In addition, food-web interactions have been shown to be of critical importance for ecosystem resistance and resilience ${ }^{120-122}$. Yet, there are numerous examples where extremes have led to transitions or even irreversible changes in ecosystem structure and composition ${ }^{12,75}$. For instance, Indian Ocean coral reefs encountered a substantial reduction in coral coverage after a severe marine heatwave in 1998 with limited recovery thereafter ${ }^{90,91}$, Australian temperate reef communities underwent an irreversible shift from kelp forests to communities typical for subtropical and tropical waters ${ }^{88}$, and major changes in zooplankton and micronekton community structure have been observed after a heatwave in the California Current System $^{36}$. Rocky intertidal communities along a $>1000$ $\mathrm{km}$ stretch of the Gulf of Alaska went through substantial declines in diversity and a transition from macroalgal to mussel coverage over several years following the "Blob" heatwave ${ }^{92}$.

Some of these long-term ecosystem transitions ${ }^{92,123}$ might have emerged as the cumulative outcome of a series of cascading effects across the levels of biological organization ${ }^{124}$. In such cascades, physiological or ecological effects at the organismal or species level are amplified within the food-web, thus leading to changes in biomass, productivity or foodweb stability and dynamics (Fig. 5). Such effects can emerge, for example, when species within a community have large differences with regard to their environmental tolerances ${ }^{75}$ (see Fig. Box 1, panel b). The resulting differential sensitivity leads to a wide range of organismal fitness and subsequently changes in population sizes and community composition during extremes, potentially causing trophic mismatches ${ }^{125}$ or collapses in predator-prey relationships ${ }^{126}$. Such transitions can include trophic reorganizations, some of which have been found to result in shortened, 'bottom-heavy' food webs 
in ecosystems where key stabilizing factors such as functional redundancy, trophic compensation and species substitution were absent ${ }^{123}$.

In addition to the consideration of the timescale of the biological response, we also need to assess the biological ramifications of the temporal evolution of an extreme event, especially its heterogeneity, and the recurrence of events. But so far, no clear trend has emerged yet from the literature, as the reported responses to recurring extremes vary from positive to negative ${ }^{127,128}$. This diverse range of responses may be linked to the degree and nature of strategies for resilience and resistance - for example, the role of high post-disturbance survivorship of recruits ${ }^{127}$. However, the reported responses may be site specific ${ }^{77}$, and dependent on the level of natural variability organisms and ecosystems encounter ${ }^{129}$ as well as on the potential preconditioning prior to the extreme $^{93}$. Also, the response of biota to heterogeneity within a multi-month extreme (Fig. Box 2, Fig. 5) can be mixed. While these changes can induce even more stress on the organisms, they may also provide some temporary respite - for days to weeks - for residents to subsist/survive ${ }^{130}$.

\section{BIOLOGICAL RESPONSES TO COMPOUND EVENTS}

Our conceptual framework in Fig. 5 also structures the discussion of the potential biological responses to compound events. At the physiological level, an energetic balance perspective such as embodied in the concept of oxygen and capacity limited thermal tolerances ${ }^{131}$ can provide a good starting point, at least for ectothermic marine animals (see also the work on the metabolic index $\left.{ }^{132,133}\right)$. In this concept, it is assumed that the realized thermal niche of an animal is limited by the level of oxygen supply at both sides of the thermal window. Thus, low oxygen concentrations matter most when an animal is at its upper thermal limit, implying strongly synergistic effects during a compound event when a marine heatwave coincides with a low oxygen extreme. An extension of this concept to include the effect of $\mathrm{CO}_{2}$, i.e., by considering hypercapnia ${ }^{131}$, predicts similar synergistic effects for a compound event characterized by a heatwave and high acidity ( see also $^{134}$ ).

Multi-dimensional fitness-landscapes in stressor space ${ }^{135}$, derived from either metaanalyses of species responses (e.g. ${ }^{97}$ ), field observations of extreme events ${ }^{83}$, targeted experiments $^{108}$, or based on novel adaptive models ${ }^{136}$ may serve to provide equivalent metrics to the metabolic index and a better understanding of the biological mechanisms driving biological responses across ecological and spatio-temporal scales. The integration of empirical evidence with mechanistic relationships between stressors and their extremes derived based on first principles of 
biology in novel adaptive marine ecosystem models ${ }^{136-138}$, or cell models ${ }^{139}$ is likely to increase our fundamental understanding of ecosystem function - a key prerequisite for improved projections of responses to extremes.

However, in order to accurately predict the response of organisms and ecosystems to extremes in multiple dimensions, these novel approaches all rely on calibration against the available data. To date, there are only a handful of examples that report the biological responses to multiple hazards associated with compound events ${ }^{78,83,84}$. In the California Current System, the combination of a marine heatwave and enhanced upwelling provided a 'natural laboratory' to explore the response of calcareous zooplankton (pteropods) to the triple hazards of high temperature and acidity, and low oxygen ${ }^{84}$. A major biological response to this compound extreme was the need for metabolic compensation, which required the reallocation of energy within the investigated pteropods. Comparative physiology of the responses of crustacean and calcareous zooplankton to this Californian compound event indicated that copepods, due to a higher capacity antioxidant defense system and vertical migratory behavior, may be better at coping with such a triple threat event $^{83}$. Due to interactive effects, the multi-faceted responses of marine life to compound events is likely more complex than that for biota encountering individual extremes, and hence the conceptual framework in Figure 5 may present a useful point of departure to explore the cumulative effects on marine biota of compound extremes.

\section{ADVANCING OUR UNDERSTANDING OF OCEAN EXTREMES}

In the last few years, ocean extremes have emerged as an issue of great concern ${ }^{140}$, especially given their potentially strong impact on marine life. Given the large socio-economic values (e.g. food security, tourism/employment) of the marine ecosystems under threat (e.g., the Great Barrier Reef ${ }^{141}$ or marine fisheries ${ }^{142,143}$ ), this represents a substantial risk for society.

We recommend three focal threads to be followed in order to advance our understanding and to mitigate this risk. The first thread should focus on a better characterization of the high acidity and low oxygen extremes. Critically, the observational basis, including the links to consequent biological impacts, needs to be drastically improved, especially in subsurface waters. Indeed, the currently available observations of the oceans' interior are often insufficient to even provide a robust baseline ${ }^{144}$, against which extremes can be detected. The increasing number of autonomous observing platforms (such as Argo profiling floats, and moored systems), often with additional biogeochemical and biological sensors ${ }^{145,146}$, provide a unique opportunity to substantially improve our ability to observe such events. These routine observations should be coupled with rapid 
response investigations when an extreme event or compound event is unfolding (guided by realtime observations and early warning systems), involving more targeted means, involving gliders, moorings, and other tools. Improved and expanding modeling capabilities will also play an important role ${ }^{13,14,54}$, especially also the establishment of cataloges of past events, for example using ocean reanalysis products ${ }^{147}$, that can be used to search for and identify the potential impact in longterm timeseries. Also, novel data analysis and synthesis approaches involving machine learning approaches to, for example, to identify compound events in high dimensional data ${ }^{148}$ can support a better characterization of extreme events.

The second thread should focus on the development of a more quantitative understanding of the processes that cause and maintain ocean extremes. A special effort will be needed to assess how the interactions between the ocean and atmosphere, and particularly their interplay at smaller scales, enhances the intrinsic variability of the system, thus generating the conditions conducive for the generation of extremes. This requires a combination of detailed analyses of observations and extensive modeling studies, especially with higher resolution models ${ }^{31,149}$. Another essential contribution is the development of a predictive capability for ocean extremes ${ }^{150}$ using both empirical as well as numerical approaches, so that impacted human communities, businesses, and leaders can prepare for extremes, by e.g., adapting strategies that reduce the exposure or minimize the magnitude of other stressors such as fishing pressure ${ }^{90}$.

The third and perhaps most important thread should focus on the study of the impacts of ocean extremes on marine life. Especially critical is the need to address two major emerging challenges. First, teasing apart and better understanding the cumulative effects on biota of the multifaceted characteristics - from abruptness to recurrence - associated with individual extremes (Box 1 and Fig. 5). Due to the potential novel range of effects of these characteristics, we will need to analyse existing datasets on multiple stressors differently, e.g., by evaluating the response of ecosystems to perturbations as a function of time. Hence, we advocate a special effort to dissect the relative roles of the characteristics associated with extremes (Fig. 5) and to determine their relative importance. For example, will the effects of abruptness on the ability of organisms to acclimate determine their subsequent responses to duration, heterogeneity, and other properties? This question could be addressed via targeted experiments to explore the relative timescales of abruptness versus acclimatory responses ${ }^{93}$.

The second challenge is the consideration of the role of the compounding effect of the different hazards, leading to a complex matrix of often novel conditions ${ }^{151}$ but further confounded by the many characteristics associated with the extremes. Approaches include manipulation experiments in situ or in vitro, and long-term monitoring, as well as new analysis methods to assess 
the biological responses such as 'early warning' bio-markers ${ }^{84}$ to provide routine in situ physiological assessments of the community. In addition, the existing large body of experimental evidence from multi-stressor research and metanalyses (see e.g. ${ }^{97}$ ) could be exploited to interpret short- to intermediate-term, physiological, developmental or population level responses. In particular, multiple stressor studies that have been fostering a mechanistic understanding and jointly developed physiological modelling approaches to understand the interplay of stressors ${ }^{152}$ should be built upon and cautiously applied to compound extremes to assess biological responses to such events.

Such mechanistic models are critical to improve also our predictive capacity of marine ecosystem impacts. This requires the continued development of novel mechanistic models that assess population dynamics based on processes at the scale of the cell ${ }^{153}$, take into account the plasticity of organisms and populations ${ }^{154}$ or the adaptive capacity of ecosystems ${ }^{136}$, and/or evaluate the dynamics of an ecosystem based on novel metagenomic and metatranscriptomic data that simultaneously provide an insight into ecosystem status and function ${ }^{139}$. Furthermore, significant advances have to be made with regard to gaps in our understanding of the factors controlling biological and functional diversity, food-web interactions and relationships between different ecosystem constituents (trophic links, symbiosis, parasitism), and also with regard to the physiological states and trophic modes (mixotrophy) of populations, before these models can be operational in forecasting and future impact projection applications.

Policy instruments, such as climate change vulnerability assessments, that permit managers to better prepare and cope with the impacts of extremes will become more critical ${ }^{155,156}$, especially when considering the expected increase in the frequency of extreme events (e.g. ${ }^{8,14}$ ). Such appraisals can be pushed farther by developing extreme-based metrics that are specifically targeted at the assessment of ocean health and societal benefits, such as the Ocean Health Index ${ }^{157}$. One option for such an index could be one that reflects the likelihood of occurrences of an extreme of a certain type and category, perhaps combined into a single metric across the three stressors. Such developments would permit the gauging of the socio-economic impact of potential changes in ocean ecosystem services emerging from extremes ${ }^{12}$. Attribution studies in well-observed systems, such as coastal coral reefs world-wide, aimed at disentangling the effects of long-term climate change trends from those of extreme events, may further help to improve our quantitative understanding of the risk that extreme events may pose to marine ecosystems within the longer term climate change context ${ }^{38,90}$. These insights may change our paradigms about what constitutes harmful/acceptable climate change ${ }^{95}$. 
Extreme events are a harbinger of the future by creating environmental conditions that the mean climate change will not generate for decades, and some recent extremes have been identified as the primary drivers of lasting, irreversible ecosystem change at the decadal scale s8,91,158. $^{8}$. Extremes pose a potentially particularly strong threat to marine organisms, since a number of the characteristics of extremes (e.g., their abrupt onset, their short duration and their high intensities) can rapidly push organisms and entire ecosystems beyond their adaptive capacity. This may lead to critical ecological transitions ${ }^{43}$ with potentially wide-reaching implications for the myriad of ecosystem services that the ocean is providing to humanity ${ }^{159,160}$.

Acknowledgments: NG, MV, and TLF acknowledge support from the Swiss National Science Foundation (project XEBUS and \#PP00P2-198897), and from the European Union's Horizon 2020 research and innovation programme under grant agreement No 820989 (project COMFORT). The work reflects only the authors' view; the European Commission and their executive agency are not responsible for any use that may be made of the information the work contains. PWB was primarily supported by the Australian Research Council through a Laureate (FL160100131). NG thanks Flora Desmet, Eike Köhn, and Joëlle Perreten for evaluating and analyzing the regional ocean biogeochemical model simulations for the Northeast Pacific "Blob" event. The GFDL ESM2M simulations were conducted by Friedrich Burger on the Swiss National Supercomputing Centre. We thank the four reviewers for their constructive reviews and inputs.

\section{AUTHOR CONTRIBUTIONS:}

NG conceived this perspective, visualized and wrote it with strong conceptual and editorial input by all co-authors. PWB and MV led the writing of the biological impact section and TF led the analyses of the global model results.

DATA/CODE availability:

The model results presented in the paper are available through the ETH Research Collection (https://www.research-collection.ethz.ch.). 


\section{Figure 1:}

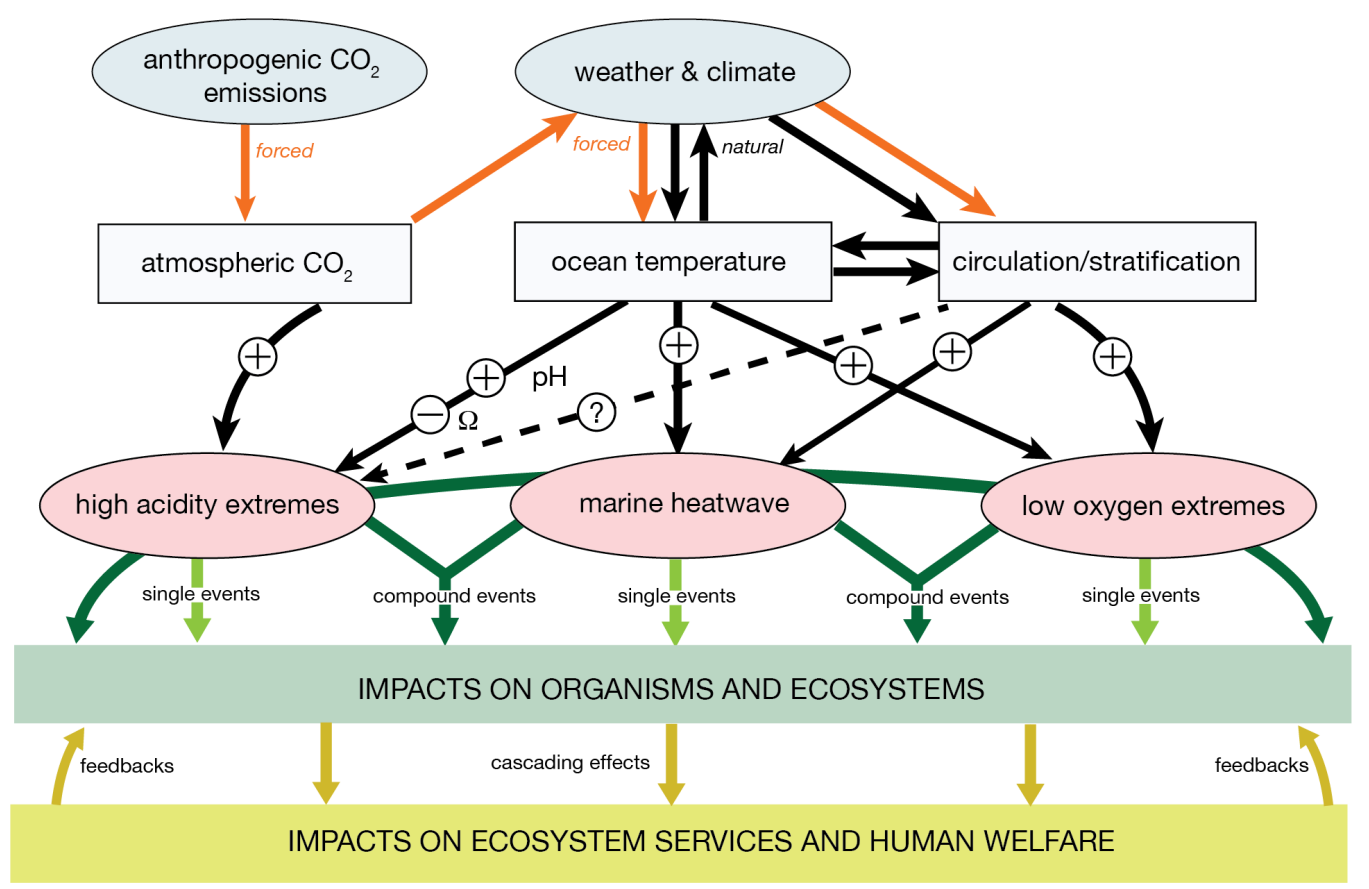

Figure 1: Drivers of marine heatwaves and ocean biogeochemical extremes and their

impact. The three types of extremes considered here, i.e., marine heatwaves, low oxygen extremes and high acidity extremes, occur in part due to natural processes (black arrows), but their intensity, frequency, and duration is strongly impacted by the anthropogenic increase in atmospheric $\mathrm{CO}_{2}$ and the resulting (human-forced) change in weather and climate (orange arrows). These three types of extremes can occur individually, but also together or in close sequence as so-called compound events. These extremes may have pronounced impacts on marine organisms and also the ecosystems that they form. Those changes, in turn, can affect key marine ecosystem services such as fisheries yields, and ultimately also human welfare through a series of cascading effects. 


\section{Figure 2:}
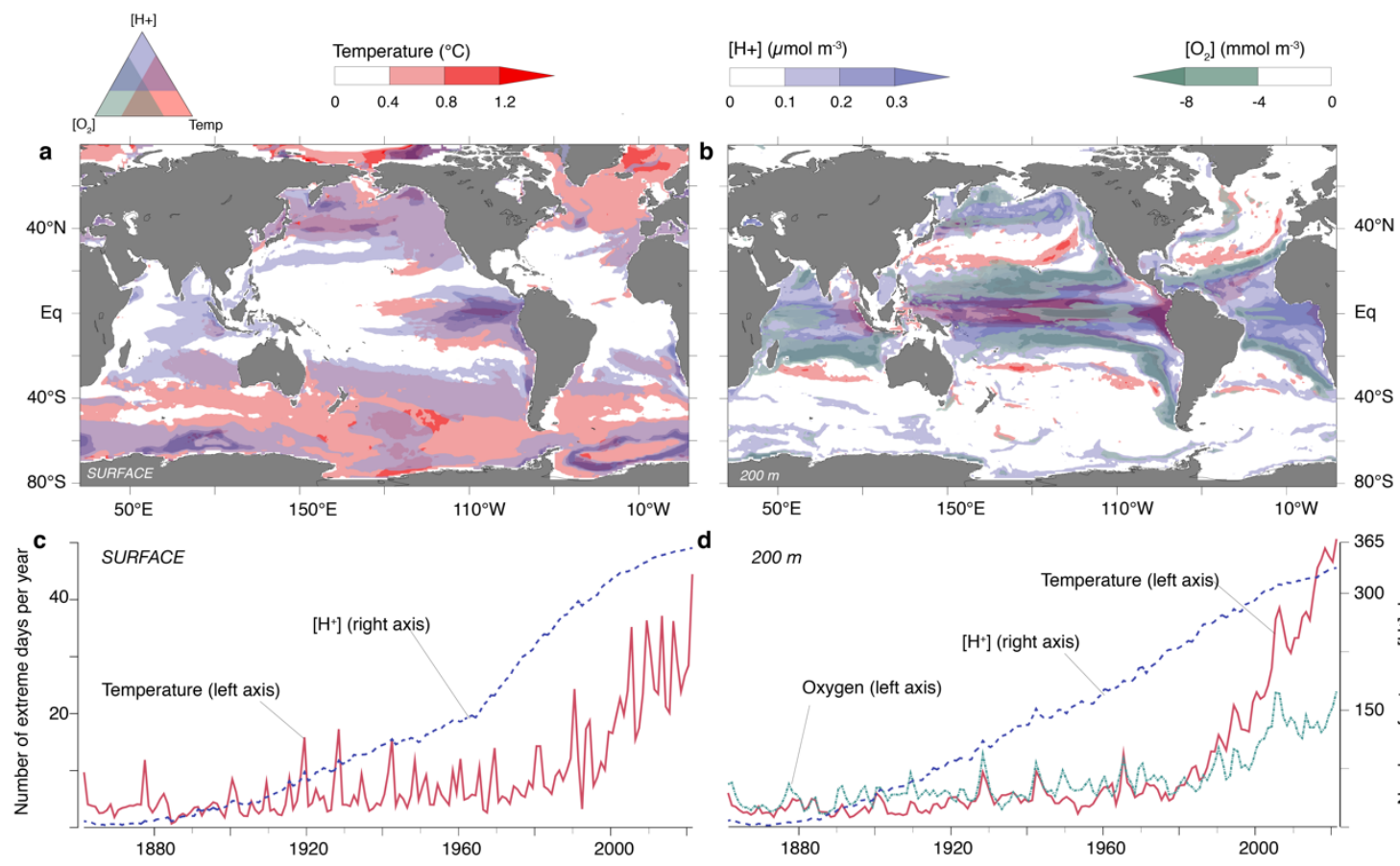

$200 \mathrm{~m}$

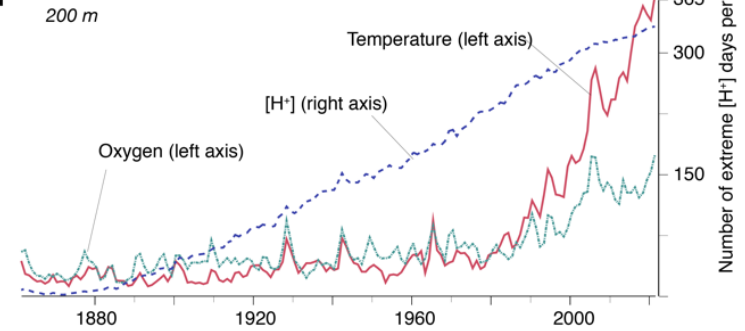

Figure 2: Global pattern and trends of marine heatwaves and biogeochemical extremes: (a)

and (b) Mean intensities of all days when the thresholds are exceeded for heatwaves (red) $\left({ }^{\circ} \mathrm{C}\right)$, high acidity extremes (blue) $\left(\mu \mathrm{mol} \mathrm{m}{ }^{-3}\right)$, and low oxygen extremes (green) $\left(\mathrm{mmol} \mathrm{m}^{-3}\right)$.

Shown are the intensities for (a) the surface layer, and (b) $200 \mathrm{~m}$ depth with the colors being mixed in regions of overlap. The extremes have been defined relative to a preindustrial control simulation. (c) and (d) Timeseries of the average number of extreme days per year at each location. Please note that the axis for the high acidity events is given on the right-hand side. All results are based on simulation results from the GFDL Earth System Model ${ }^{14}$. 


\section{Figure 3:}
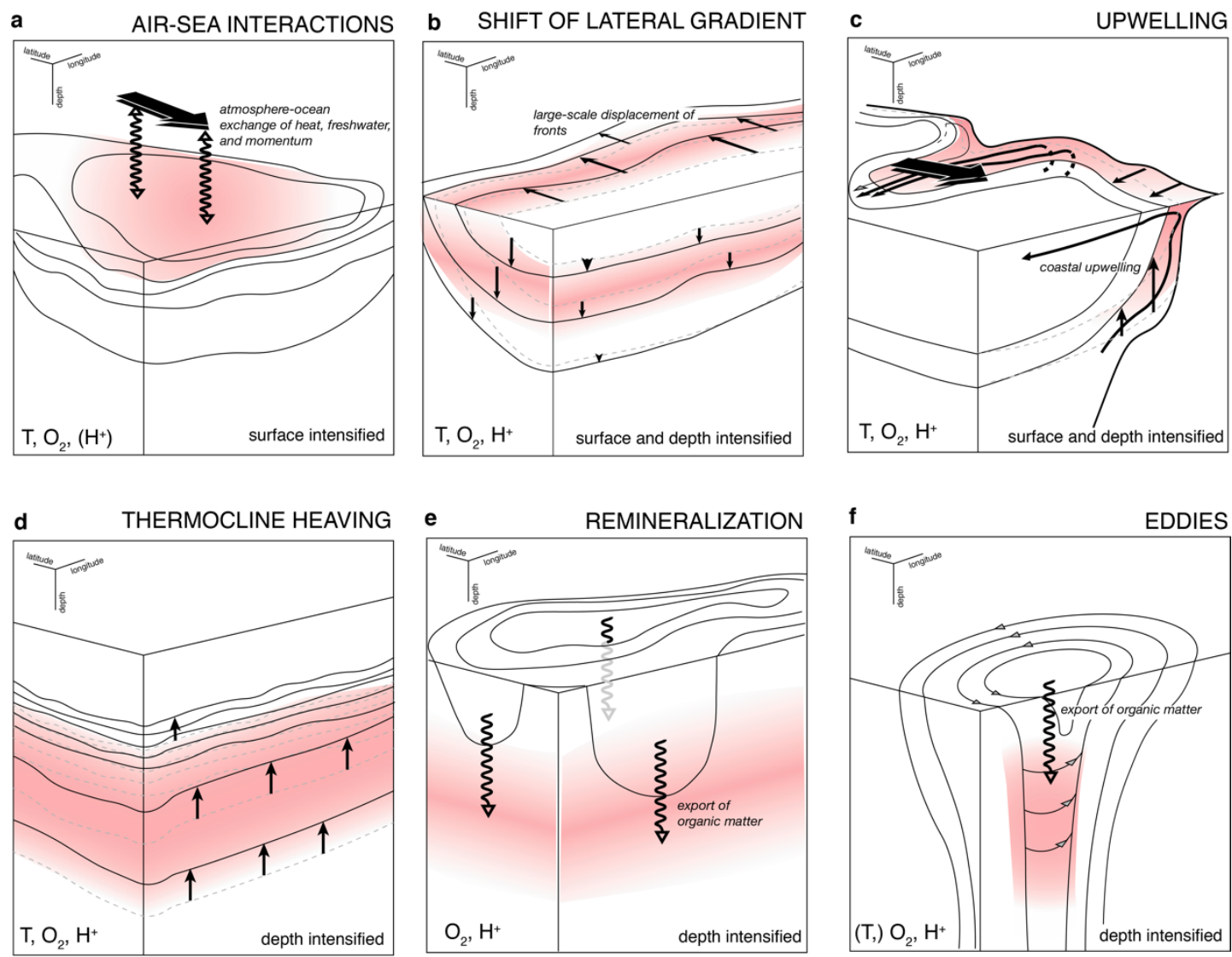

Figure 3: Idealized depictions of the mechanisms giving rise to extreme conditions in

temperature, acidity, and oxygen. (a) Air-sea interactions, (b) lateral shifts of fronts (at the surface or at depth), (c) upwelling (shown here is coastal upwelling, but the same processes are at work also at the equator), (d) thermocline displacement, (e) enhanced remineralization of settling organic matter, and (f) eddy trapping. Not all variables are affected equally, as indicated on the bottom left of each panel. 


\section{Figure 4:}

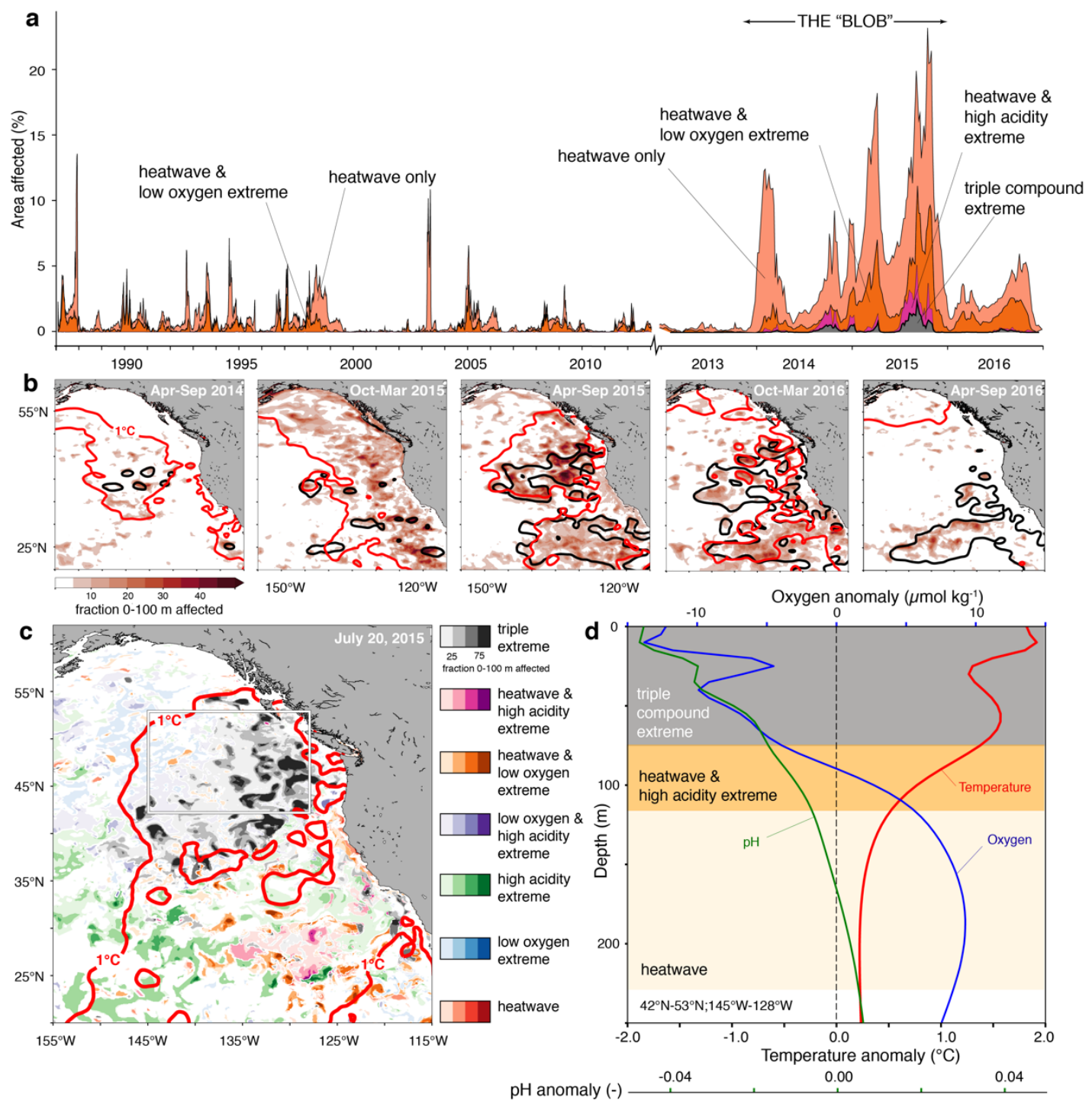

Figure 4: Illustration of the temporal evolution and four-dimensional nature of ocean extremes using model simulation results for the 2013-2015 "Blob". (a) Temporal evolution of the fractional area $\left(20^{\circ} \mathrm{N}-60^{\circ} \mathrm{N}, 115^{\circ} \mathrm{W}-155^{\circ} \mathrm{W}\right)$ that is subject to a marine heatwave or any compound event. An event contributes to this metric when at least $25 \%$ of the top $100 \mathrm{~m}$ of the water column is considered extreme for the considered properties. (b) Modeled spatial evolution of the temperature characteristics of the Blob event. The color filled contours depicts the average fraction of the top $100 \mathrm{~m}$ of the water column that is identified as a temperature extreme. The red and black contours represent the $1^{\circ} \mathrm{C}$ anomaly of temperature at the surface and at a depth of $100 \mathrm{~m}$, respectively. They thus identify the extent of the "Blob". (c) Snapshot of the modeled fields for July 20, 2015. The color indicates the type, while the saturation shows the fraction of the water column $(0-100 \mathrm{~m})$ 
that is occupied by these extreme conditions. The white box off the western seaboard in panel (c) indicates the area over which the vertical profile show in (d) is averaged. All figures are based on a hindcast simulation using a regional ocean biogeochemical model ${ }^{69}$ with the extremes being defined relative to a modern reference period (1986 to 2016). 


\section{Figure 5:}

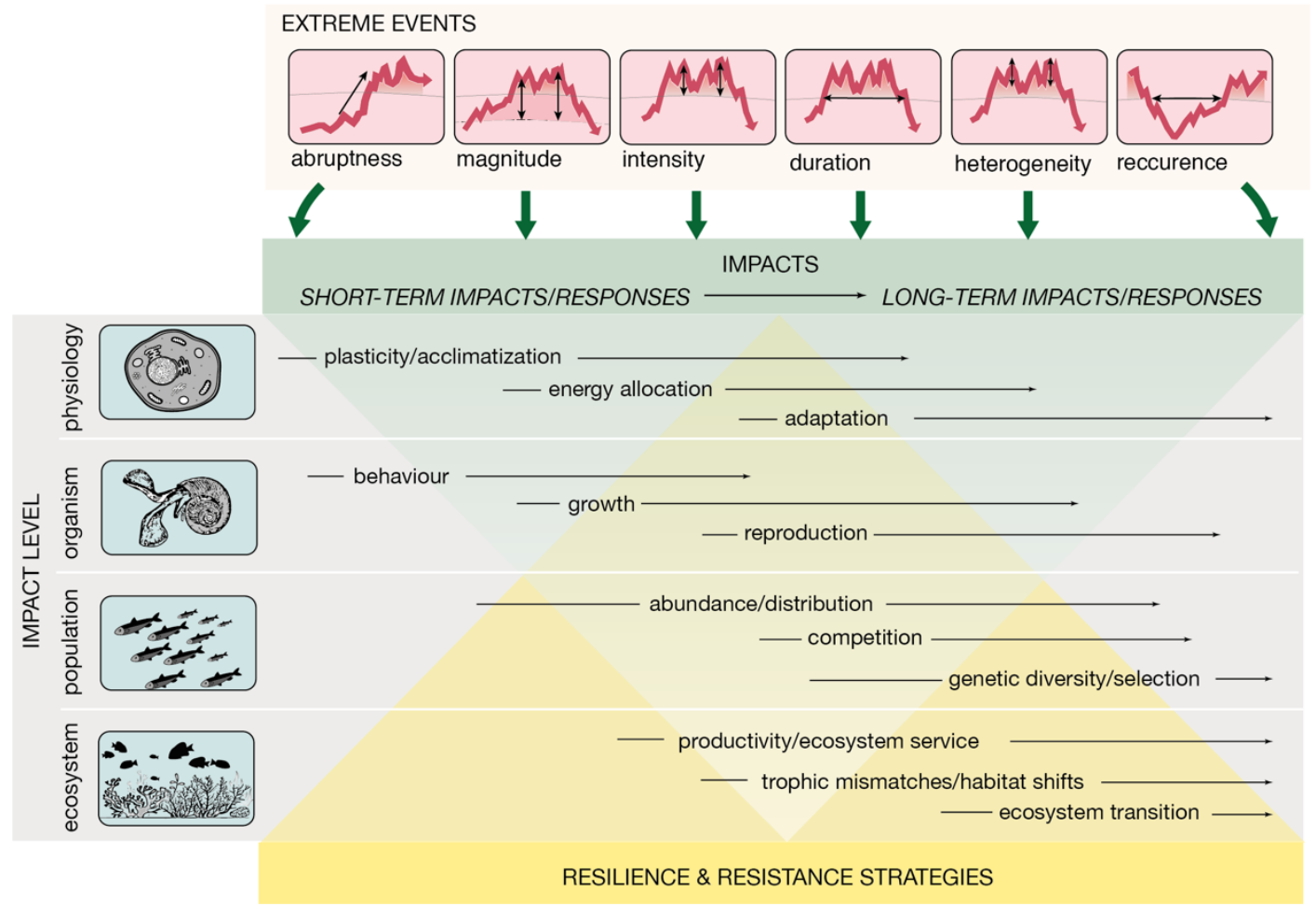

Figure 5: Conceptual framework to understand the impact of marine biogeochemical extremes and heatwaves on the functioning of marine life - from physiology through to ecosystems. The timescales of the biological impacts and responses relate also to the range of characteristics used to define extremes (Fig. Box 2) from short-term (days, abrupt onset of extremes) to long-term (years, recurring events, such as the 2016 and 2017 bleaching events of the Great Barrier Reef ${ }^{128}$. Better understanding of the effectiveness of resilience and resistance strategies to extremes will be essential to more accurately project the range of biological responses, such as adaptive capacity, which may include two classes of responses, i.e., "persist in place" and "shift in space"114. A major unknown is the change in resilience of biota that may occur with the projected increase in the frequency of disturbances driven by extreme events ${ }^{117}$. 


\section{BOXES}

\section{BOX 1: Definition of extreme events}

Any method used to identify extreme events needs to make several key choices based on the scientific question to be addressed ( $\mathrm{cf}^{~}{ }^{7}$ ). First, one needs to decide on the type of threshold, i.e., relative versus absolute (Fig. Box, panels a \& b). Relative thresholds are based on the local variability in the stress variable (e.g., temperature percentiles). Their use is warranted in situations where one expects that organisms are adapted to cope with the normal range of variability, but challenged when the conditions move outside this range ${ }^{129}$. In contrast, absolute thresholds are warranted in situations when the stress variable can move outside the physiological limits of marine organisms or can cross a physical or biogeochemical thresholds. (Fig. Box, panel b). The second decision, required only in the case of a relative threshold, is the reference period, i.e., the period that is used to construct the probability density function, and whether this reference period is fixed or moves with time, i.e., whether one uses a fixed or a so-called shifting baseline ${ }^{10}$. The third choice involves how seasonality is dealt with, i.e., whether the thresholds are determined from seasonallyvarying data or from deseasonalized data. The fourth and final choice concerns the requirement of additional conditions, such as, for example, a certain minimum duration.

The basis for the decision about these choices rests primarily on the biological impact to be quantified - assessments of impacts at the ecosystem level have often taken a relative threshold approach, such as in the case of coral bleaching ${ }^{161}$. In contrast, physiological impacts at the organism level have often used absolute thresholds that reflect specific limits of metabolic processes. For marine heatwaves, most studies have used a relative threshold approach, but with varying choices with regard to the consideration of seasonality ${ }^{8,30}$. Absolute thresholds tend to be more commonly used to study extremes with high acidity ${ }^{13}$ or low oxygen, although relative thresholds have also been used ${ }^{14}$. A typical absolute threshold is the saturation level with regard to mineral $\mathrm{CaCO}_{3}, \Omega=1$, i.e., when seawater changes from being supersaturated $(\Omega>1)$ to becoming undersaturated $(\Omega<1)$, thus leading to $\mathrm{CaCO}_{3}$ shell dissolution. Analogous absolute thresholds for the definition of oxygen extremes would be the hypoxic limit $\left(\sim 6 \mu \mathrm{mol} \mathrm{kg}^{-1}\right)$ or the suboxic/anoxic limit $\left(\sim 5 \mu \mathrm{mol} \mathrm{kg}{ }^{-1}\right)$, below which metabolic and physiological processes in heterotrophs are impaired. 

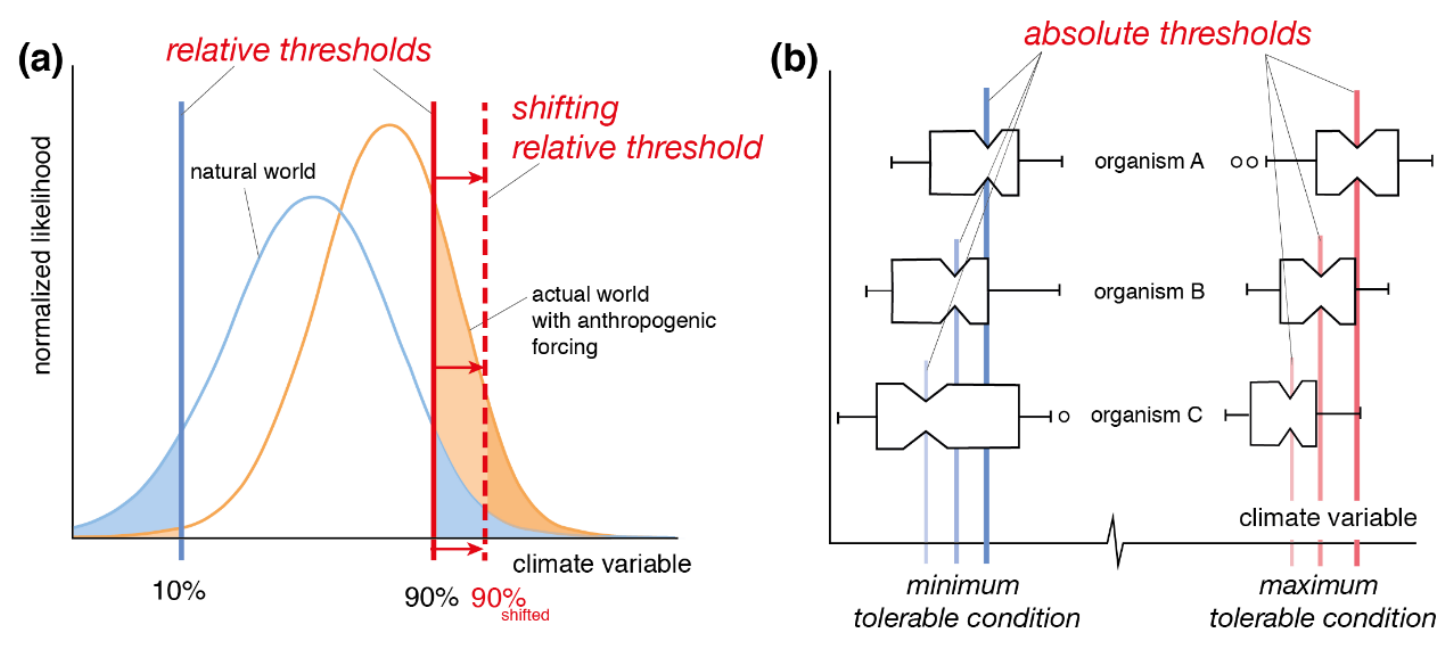

Fig. BOX 1: Concepts associated with the definitions of extreme events. (a) Relative thresholds determined from the perspective of the statistical distribution, here based on the 10th or 90th percentile. The relative thresholds are usually defined from the probability density function for a fixed reference period (fixed baseline). But the relative thresholds can also be defined from a probability density function that evolves with time, i.e., defining a shifting relative threshold (shifting baseline). (b) Absolute thresholds determined from the perspective of tolerable conditions for organisms, either near their estimated minimum or their maximum tolerable conditions. Here, a range of thresholds are shown for organisms A-C to reflect differences in their sensitivity to extremes ${ }^{75}$. 


\section{BOX 2: Key characteristics of extreme events [currently 168 words]}

Extreme events can be characterized by multiple characteristics (Fig. Box 2): The most commonly used ones are the number of days and the duration, i.e., the number of days and the time period during which this threshold was exceeded, and the intensity, i.e., how much the climate variable has remained, on average, above the threshold during the event. Closely related to the intensity is the magnitude, as it reflects the mean value of the climate variable during the event relative to its climatological mean. Less common, but physiologically and ecologically influential is the abruptness and the heterogeneity. The former describes the speed of the onset, while the latter reflects the variance of the intensity during an event. The final characteristics considered here is the recurrence, i.e., the average time between events at a particular location. Intensity and duration are sometimes combined to form an integrated metric, often referred to as cumulative intensity, degree heating weeks, or severity (defined as the product of mean intensity and duration). This metric plays an important role for coral bleaching, for example ${ }^{162}$. The seasonal distribution of extreme events will also be critical for the quantification of impacts at the population level (e.g. occurrence of extremes during reproductive periods), as the susceptibility to disruption can be lifestage dependent ${ }^{163}$, and thus may vary seasonally.

The relevance of these extreme characteristics with regard to ecosystem impacts will depend on the taxa under study, but also on the level of biological organization at which these effects are evaluated. Whereas metrics such as intensity, duration or recurrence have been shown to correlate with impacts at both the organism and ecosystem level ${ }^{93}$, abruptness will matter in relation to the rapidity of the acclimatory response of specific physiological processes ${ }^{102}$. Recurrence rate will have impacts at the population level such as reproductive success, or for the magnitude and permanence of adaptive responses ${ }^{141}$. The heterogeneity of events may be indicative of the degree to which refuges are created that provide a respite from stressful conditions ${ }^{85,127}$. While relationships between event metrics and specific responses at the organism or population level can be quantified in targeted experiments, such dependencies may be challenging to disentangle in situ and at the ecosystem level due to a superimposition of multiple effects (ranging from acclimatory and competitive responses to community reshuffling and habitat shifts occurring at different spatiotemporal scales; Fig. 5). 


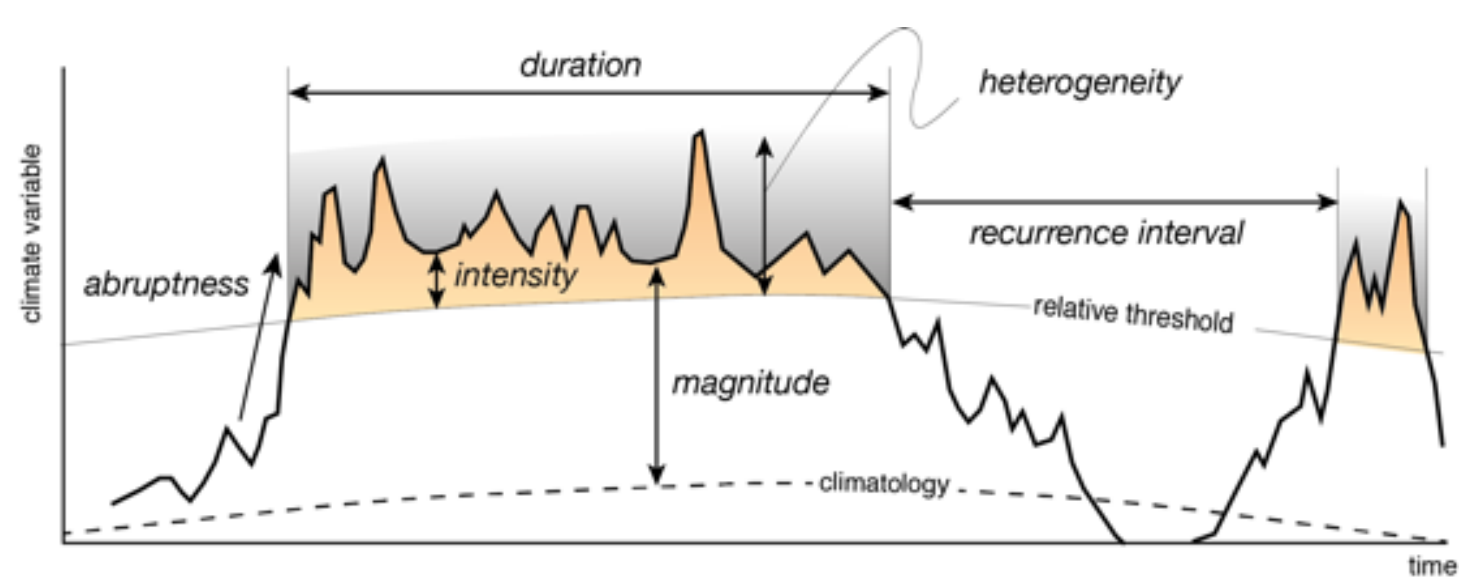

Fig. BOX 2: Metrics associated with an extreme event, i.e., the intensity, magnitude, duration, heterogeneity, abruptness, and recurrence (see text for definitions). 


\section{REFERENCES}

1. Gruber, N. Warming up, turning sour, losing breath: ocean biogeochemistry under global change. Philos. Trans. A. Math. Phys. Eng. Sci. 369, 1980-96 (2011).

Identifies the potential synegistic threat to marine ecosystems emanating from ocean warming, deoxygenation and acidification

2. Gattuso, J.-P. et al. Contrasting futures for ocean and society from different anthropogenic CO2 emissions scenarios. Science (80-. ). 349, aac4722-aac4722 (2015).

3. Breitburg, D. et al. Declining oxygen in the global ocean and coastal waters. Science (80-. ). 359, eaam7240 (2018).

4. Cheng, L. et al. Improved estimates of ocean heat content from 1960 to 2015. Sci. Adv. 3, e1601545 (2017).

5. Bopp, L. et al. Multiple stressors of ocean ecosystems in the 21 st century: projections with CMIP5 models. Biogeosciences 10, 6225-6245 (2013).

6. Kwiatkowski, L. et al. Twenty-first century ocean warming, acidification, deoxygenation, and upper-ocean nutrient and primary production decline from CMIP6 model projections. Biogeosciences 17, 3439-3470 (2020).

7. Oliver, E. C. J. et al. Marine Heatwaves. Ann. Rev. Mar. Sci. 13, annurev-marine-032720095144 (2021).

8. Frölicher, T. L., Fischer, E. M. \& Gruber, N. Marine heatwaves under global warming. Nature 560, 360-364 (2018).

Quantify the future evolution of marine heatwaves under different climate scenarios and their attribution to climate change

9. Oliver, E. C. J. et al. Longer and more frequent marine heatwaves over the past century. Nat. Commun. 9, 1324 (2018).

Highlight the strong increase in the occurrence and intensity of marine heatwaves in recent decades.

10. Oliver, E. C. J. et al. Projected Marine Heatwaves in the 21st Century and the Potential for Ecological Impact. Front. Mar. Sci. 6, 1-12 (2019).

11. Benedetti-Cecchi, L. Complex networks of marine heatwaves reveal abrupt transitions in the global ocean. Sci. Rep. 11, 1-11 (2021).

12. Smale, D. A. et al. Marine heatwaves threaten global biodiversity and the provision of ecosystem services. Nat. Clim. Chang. 9, 306-312 (2019).

Assess the potential for global ocean ecosystem impacts of marine heatwaves.

13. Hauri, C., Gruber, N., McDonnell, A. M. P. \& Vogt, M. The intensity, duration, and 
severity of low aragonite saturation state events on the California continental shelf. Geophys. Res. Lett. 40, 3424-3428 (2013).

\section{Model the evolution of ocean acidification related extremes in the California Current System}

14. Burger, F. A., John, J. G. \& Frölicher, T. L. Increase in ocean acidity variability and extremes under increasing atmospheric CO2. Biogeosciences 17, 4633-4662 (2020).

15. Wernberg, T. et al. An extreme climatic event alters marine ecosystem structure in a global biodiversity hotspot. Nat. Clim. Chang. 3, 78-82 (2012).

Demonstrate profound ocean ecosystem changes in response to a heatwave.

16. Seneviratne, S. I. et al. Changes in Climate Extremes and their Impacts on the Natural Physical Environment. in Managing the Risks of Extreme Events and Disasters to Advance Climate Change Adaptation (eds. Field, C. B., Barros, V., Stocker, T. F. \& Dahe, Q.) 109230 (Cambridge University Press, 2012). doi:10.1017/CBO9781139177245.006.

17. Friedlingstein, P. et al. Global Carbon Budget 2020. Earth Syst. Sci. Data 12, 3269-3340 (2020).

18. Keeling, R. F., Kortzinger, A. \& Gruber, N. Ocean Deoxygenation in a Warming World. Ann. Rev. Mar. Sci. 2, 199-229 (2010).

19. Li, G. et al. Increasing ocean stratification over the past half-century. Nat. Clim. Chang. (2020) doi:10.1038/s41558-020-00918-2.

20. Sallée, J. B. et al. Summertime increases in upper-ocean stratification and mixed-layer depth. Nature 591, 592-598 (2021).

21. Sarmiento, J. L. \& Gruber, N. Ocean Biogeochemical Dynamics. (Princeton University Press, 2006).

22. Mikaloff Fletcher, S. E. et al. Inverse estimates of anthropogenic CO2 uptake, transport, and storage by the ocean. Global Biogeochem. Cycles 20, 1-16 (2006).

23. Doney, S. C., Fabry, V. J., Feely, R. A. \& Kleypas, J. A. Ocean Acidification: The other CO2 problem. Ann. Rev. Mar. Sci. 1, 169-192 (2009).

24. Doney, S. C., Busch, D. S., Cooley, S. R. \& Kroeker, K. J. The Impacts of Ocean Acidification on Marine Ecosystems and Reliant Human Communities. Annu. Rev. Environ. Resour. 45, 83-112 (2020).

25. Kroeker, K. J., Kordas, R. L., Crim, R. N. \& Singh, G. G. Meta-analysis reveals negative yet variable effects of ocean acidification on marine organisms. Ecol. Lett. 13, 1419-1434 (2010).

26. Mollica, N. R. et al. Ocean acidification affects coral growth by reducing skeletal density. 
Proc. Natl. Acad. Sci. U. S. A. 115, 1754-1759 (2018).

27. Lavell, A. et al. Climate change: New dimensions in disaster risk, exposure, vulnerability, and resilience. in Managing the Risks of Extreme Events and Disasters to Advance Climate Change Adaptation (eds. Field, C. B. et al.) 25-64 (2012).

28. Parmesan, C., Root, T. L. \& Willig, M. R. Impacts of Extreme Weather and Climate on Terrestrial Biota. Bull. Am. Meteor. Soc. 81, 443-450 (2000).

29. Smith, M. D. An ecological perspective on extreme climatic events: a synthetic definition and framework to guide future research. J. Ecol. 99, 656-663 (2011).

30. Hobday, A. J. et al. A hierarchical approach to defining marine heatwaves. Prog. Oceanogr. 141, 227-238 (2016).

31. Holbrook, N. J. et al. A global assessment of marine heatwaves and their drivers. Nat. Commun. 10, 1-13 (2019).

32. Huang, B. et al. Extended reconstructed sea surface temperature version 4 (ERSST.v4). Part I: Upgrades and intercomparisons. J. Clim. 28, 911-930 (2015).

33. Gentemann, C. L., Fewings, M. R. \& García-Reyes, M. Satellite sea surface temperatures along the West Coast of the United States during the 2014-2016 northeast Pacific marine heat wave. Geophys. Res. Lett. 44, 312-319 (2017).

34. Cavole, L. et al. Biological Impacts of the 2013-2015 Warm-Water Anomaly in the Northeast Pacific: Winners, Losers, and the Future. Oceanography 29, (2016).

\section{Synthesize the ecosystem impacts of the 2103-2015 "Blob" heatwave}

35. Di Lorenzo, E. \& Mantua, N. Multi-year persistence of the 2014/15 North Pacific marine heatwave. Nat. Clim. Chang. 6, 1-7 (2016).

36. Brodeur, R. D., Auth, T. D. \& Phillips, A. J. Major shifts in pelagic micronekton and macrozooplankton community structure in an upwelling ecosystem related to an unprecedented marine heatwave. Front. Mar. Sci. 6, 1-15 (2019).

37. Cheung, W. W. L. \& Frölicher, T. L. Marine heatwaves exacerbate climate change impacts for fisheries in the northeast Pacific. Sci. Rep. 10, 6678 (2020).

38. Laufkötter, C., Zscheischler, J. \& Frölicher, T. L. High-impact marine heatwaves attributable to human-induced global warming. Science 369, 1621-1625 (2020).

39. Leonard, M. et al. A compound event framework for understanding extreme impacts. Wiley Interdiscip. Rev. Clim. Chang. 5, 113-128 (2014).

40. Zscheischler, J. et al. Future climate risk from compound events. Nat. Clim. Chang. 8, 1 (2018).

41. Le Grix, N., Zscheischler, J., Laufkötter, C., Rousseaux, C. S. \& Frölicher, T. L. 
Compound high-temperature and low-chlorophyll extremes in the ocean over the satellite period. Biogeosciences 18, 2119-2137 (2021).

42. Boyd, P. W. \& Brown, C. J. Modes of interactions between environmental drivers and marine biota. Front. Mar. Sci. 2, 1-7 (2015).

43. Trisos, C. H., Merow, C. \& Pigot, A. L. The projected timing of abrupt ecological disruption from climate change. Nature 1-6 (2020) doi:10.1038/s41586-020-2189-9.

44. Limburg, K. E., Breitburg, D., Swaney, D. P. \& Jacinto, G. Ocean Deoxygenation: A Primer. One Earth 2, 24-29 (2020).

45. Dunne, J. P. et al. GFDL's ESM2 global coupled climate-carbon earth system models. Part II: Carbon system formulation and baseline simulation characteristics. J. Clim. 26, 2247-2267 (2013).

46. Dunne, J. P. et al. GFDL's ESM2 Global Coupled Climate-Carbon Earth System Models. Part I: Physical Formulation and Baseline Simulation Characteristics. J. Clim. 25, 66466665 (2012).

47. Allen, M. R. et al. Global Warming of $1.5^{\circ} \mathrm{C}$. Framing and Context. in An IPCC Special Report on the impacts of global warming of $1.5^{\circ} \mathrm{C}$ above pre-industrial levels and related global greenhouse gas emission pathways, in the context of strengthening the global response to the threat of climate change, (eds. Masson-Delmotte, V. et al.) 49-91 (2018).

48. Frölicher, T. L. \& Laufkötter, C. Emerging risks from marine heat waves. Nat. Commun. 9, 650 (2018).

49. Pilo, G. S., Holbrook, N. J., Kiss, A. E. \& Hogg, A. M. C. Sensitivity of Marine Heatwave Metrics to Ocean Model Resolution. Geophys. Res. Lett. 46, 14604-14612 (2019).

50. Schlegel, R. W., Oliver, E. C. J., Hobday, A. J. \& Smit, A. J. Detecting Marine Heatwaves With Sub-Optimal Data. Front. Mar. Sci. 6, 1-14 (2019).

51. Hobday, A. et al. Categorizing and Naming Marine Heatwaves. Oceanography 31, (2018).

52. Alexander, M. A. et al. The Atmospheric Bridge: The Influence of ENSO

Teleconnections on Air - Sea Interaction over the Global Oceans. J. Clim. 15, 2205-2231 (2002).

53. Amaya, D. J., Miller, A. J., Xie, S. P. \& Kosaka, Y. Physical drivers of the summer 2019 North Pacific marine heatwave. Nat. Commun. 11, 1-9 (2020).

54. Negrete-García, G., Lovenduski, N. S., Hauri, C., Krumhardt, K. M. \& Lauvset, S. K. Sudden emergence of a shallow aragonite saturation horizon in the Southern Ocean. Nat. Clim. Chang. 9, 313-317 (2019).

55. Schaeffer, A. \& Roughan, M. Subsurface intensification of marine heatwaves off 
southeastern Australia: The role of stratification and local winds. Geophys. Res. Lett. 44, 5025-5033 (2017).

56. Jackson, J. M., Johnson, G. C., Dosser, H. V. \& Ross, T. Warming From Recent Marine Heatwave Lingers in Deep British Columbia Fjord. Geophys. Res. Lett. 45, 9757-9764 (2018).

57. Scannell, H. A., Johnson, G. C., Thompson, L., Lyman, J. M. \& Riser, S. C. Subsurface Evolution and Persistence of Marine Heatwaves in the Northeast Pacific. Geophys. Res. Lett. 47, 1-10 (2020).

58. Deutsch, C., Brix, H., Ito, T., Frenzel, H. \& Thompson, L. Climate-forced variability of ocean hypoxia. Science 333, 336-9 (2011).

59. Frenger, I. et al. Biogeochemical Role of Subsurface Coherent Eddies in the Ocean: Tracer Cannonballs, Hypoxic Storms, and Microbial Stewpots? Global Biogeochem. Cycles 32, 226-249 (2018).

60. Schütte, F. et al. Characterization of 'dead-zone' eddies in the eastern tropical North Atlantic. Biogeosciences 13, 5865-5881 (2016).

61. Lauvset, S. K. et al. Processes Driving Global Interior Ocean pH Distribution. Global Biogeochem. Cycles 34, 1-17 (2020).

62. Gaube, P., Chelton, D. B., Strutton, P. G. \& Behrenfeld, M. J. Satellite observations of chlorophyll, phytoplankton biomass, and Ekman pumping in nonlinear mesoscale eddies. J. Geophys. Res. Ocean. 118, 6349-6370 (2013).

63. Frenger, I., Münnich, M., Gruber, N. \& Knutti, R. Southern Ocean eddy phenomenology. J. Geophys. Res. Ocean. 120, 7413-7449 (2015).

64. Hauss, H. et al. Dead zone or oasis in the open ocean? Zooplankton distribution and migration in low-oxygen modewater eddies. Biogeosciences 13, 1977-1989 (2016).

65. Gruber, N. et al. Rapid progression of ocean acidification in the California Current System. Science 337, 220-3 (2012).

66. Santora, J. A. et al. Habitat compression and ecosystem shifts as potential links between marine heatwave and record whale entanglements. Nat. Commun. 11, 1-12 (2020).

67. Bond, N. A., Cronin, M. F., Freeland, H. \& Mantua, N. Causes and impacts of the 2014 warm anomaly in the NE Pacific. Geophys. Res. Lett. 42, 3414-3420 (2015).

68. Peterson, W. T., Bond, N. A. \& Robert, M. The Blob ( Part Three ): Going, going, gone ? PICES Press 24, 46-48 (2016).

69. Frischknecht, M., Münnich, M. \& Gruber, N. Local atmospheric forcing driving an unexpected California Current System response during the 2015-2016 El Niño. Geophys. 
Res. Lett. 44, 304-311 (2017).

70. Pörtner, H. O. \& Knust, R. Climate Change Affects Marine Fishes Through the Oxygen Limitation of Thermal Tolerance. Science (80-. ). 315, 95-97 (2007).

71. Penn, J. L., Deutsch, C., Payne, J. L. \& Sperling, E. A. Temperature-dependent hypoxia explains biogeography and severity of end-Permian marine mass extinction. Science (80-. ). 362, (2018).

72. Dahlke, F. T., Wohlrab, S., Butzin, M. \& Pörtner, H.-O. Thermal bottlenecks in the life cycle define climate vulnerability of fish. Science (80-. ). 369, 65-70 (2020).

73. Pörtner, H. O. Ecosystem effects of ocean acidification in times of ocean warming: A physiologist's view. Mar. Ecol. Progr. Ser. 373, 203-217 (2008).

74. Stillman, J. H. Heat waves, the new normal: Summertime temperature extremes will impact animals, ecosystems, and human communities. Physiology 34, 86-100 (2019).

75. Straub, S. C. et al. Resistance, Extinction, and Everything in Between - The Diverse Responses of Seaweeds to Marine Heatwaves. Front. Mar. Sci. 6, 1-13 (2019).

76. Hughes, T. P. et al. Spatial and temporal patterns of mass bleaching of corals in the Anthropocene. Science (80-. ). 5, 80-83 (2018).

\section{Demonstrate the global-scale impact of marine heatwaves on warm water corals}

77. Donovan, M. K. et al. Local conditions magnify coral loss following marine heatwaves. Science (80-. ). 980, 977-980 (2021).

78. Klein, S. G. et al. Projecting coral responses to intensifying marine heatwaves under ocean acidification. Global Change Biology (2021). doi:10.1111/gcb.15818.

79. McMahon, B. R. Physiological Responses to Oxygen Depletion in Intertidal Animals. Am. Zool. 28, 39-53 (1988).

80. Kroeker, K. J. et al. Ecological change in dynamic environments: Accounting for temporal environmental variability in studies of ocean change biology. Glob. Chang. Biol. 26, 54 67 (2020).

81. Hofmann, G. E. et al. High-frequency dynamics of ocean $\mathrm{pH}$ : a multi-ecosystem comparison. PLoS One 6, e28983 (2011).

82. Spisla, C. et al. Extreme Levels of Ocean Acidification Restructure the Plankton Community and Biogeochemistry of a Temperate Coastal Ecosystem: A Mesocosm Study. Front. Mar. Sci. 7, 1-24 (2021).

83. Engström-Öst, J. et al. Eco-physiological responses of copepods and pteropods to ocean warming and acidification. Sci. Rep. 9, 1-13 (2019).

84. Bednaršek, N. et al. El Niño-Related Thermal Stress Coupled With Upwelling-Related 
Ocean Acidification Negatively Impacts Cellular to Population-Level Responses in Pteropods Along the California Current System With Implications for Increased Bioenergetic Costs. Front. Mar. Sci. 5, 1-17 (2018).

Show the impact of a compound event on pteropods, a keystone zooplankton species in many marine ecosystems.

85. Calderón-Liévanos, S. et al. Survival and respiration of green abalone ( Haliotis fulgens ) facing very short-term marine environmental extremes. Mar. Freshw. Behav. Physiol. 52, $1-15$ (2019).

86. Mieszkowska, N., Burrows, M. T., Hawkins, S. J. \& Sugden, H. Impacts of Pervasive Climate Change and Extreme Events on Rocky Intertidal Communities: Evidence From Long-Term Data. Front. Mar. Sci. 8, (2021).

87. Nielsen, J. M. et al. Responses of ichthyoplankton assemblages to the recent marine heatwave and previous climate fluctuations in several Northeast Pacific marine ecosystems. Glob. Chang. Biol. 506-520 (2020) doi:10.1111/gcb.15415.

88. Wernberg, T. et al. Climate-driven regime shift of a temperate marine ecosystem. Science (80-. ). 353, 169-172 (2016).

89. Garrabou, J. et al. Mass mortality in Northwestern Mediterranean rocky benthic communities: Effects of the 2003 heat wave. Glob. Chang. Biol. 15, 1090-1103 (2009).

90. Darling, E. S., McClanahan, T. R. \& Côté, I. M. Life histories predict coral community disassembly under multiple stressors. Glob. Chang. Biol. 19, 1930-1940 (2013).

91. Ateweberhan, M., McClanahan, T. R., Graham, N. A. J. \& Sheppard, C. R. C. Episodic heterogeneous decline and recovery of coral cover in the Indian Ocean. Coral Reefs $\mathbf{3 0}$, 739-752 (2011).

92. Weitzman, B. et al. Changes in Rocky Intertidal Community Structure During a Marine Heatwave in the Northern Gulf of Alaska. Front. Mar. Sci. 8, (2021).

93. Samuels, T., Rynearson, T. A. \& Collins, S. Surviving Heatwaves: Thermal Experience Predicts Life and Death in a Southern Ocean Diatom. Front. Mar. Sci. 8, (2021).

94. Vajedsamiei, J., Wahl, M., Schmidt, A. L., Yazdanpanahan, M. \& Pansch, C. The Higher the Needs, the Lower the Tolerance: Extreme Events May Select Ectotherm Recruits With Lower Metabolic Demand and Heat Sensitivity. Front. Mar. Sci. 8, 1-10 (2021).

95. Bindoff, N. L. et al. Ocean, Marine Ecosystems, and Dependent Communities. in IPCC Special Report on the Ocean and Cryosphere in a Changing Climate (eds. Pörtner, H.-O. et al.) nn (2021).

96. Pörtner, H.-O. \& Karl, D. M. Chapter 6. Ocean Systems. in IPCC WGII AR5 (IPCC, 
2014).

97. Harvey, B. P., Gwynn-Jones, D. \& Moore, P. J. Meta-analysis reveals complex marine biological responses to the interactive effects of ocean acidification and warming. Ecol. Evol. 3, 1016-30 (2013).

98. Gunderson, A. R., Armstrong, E. J. \& Stillman, J. H. Multiple Stressors in a Changing World: The Need for an Improved Perspective on Physiological Responses to the Dynamic Marine Environment. Ann. Rev. Mar. Sci. 8, 357-378 (2016).

99. Seifert, M., Rost, B., Trimborn, S. \& Hauck, J. Meta-analysis of multiple driver effects on marine phytoplankton highlights modulating role of pCO2. Glob. Chang. Biol. 26, 67876804 (2020).

100. Sampaio, E. et al. Impacts of hypoxic events surpass those of future ocean warming and acidification. Nat. Ecol. Evol. (2021) doi:10.1038/s41559-020-01370-3.

101. Bernhardt, J. R., O’Connor, M. I., Sunday, J. M. \& Gonzalez, A. Life in fluctuating environments: Adaptation to changing environments. Philos. Trans. R. Soc. B Biol. Sci. 375, (2020).

102. Somero, G. N. The cellular stress response and temperature: Function, regulation, and evolution. J. Exp. Zool. Part A Ecol. Integr. Physiol. 333, 379-397 (2020).

103. Fordyce, A. J., Ainsworth, T. D., Heron, S. F. \& Leggat, W. Marine heatwave hotspots in coral reef environments: Physical drivers, ecophysiological outcomes and impact upon structural complexity. Front. Mar. Sci. 6, 1-17 (2019).

104. Krueger, T. et al. Antioxidant plasticity and thermal sensitivity in four types of Symbiodinium sp. J. Phycol. 50, 1035-1047 (2014).

105. Reusch, T. B. H. \& Boyd, P. W. Experimental Evolution Meets Marine Phytoplankton. Evolution (N. Y). 67, 1849-1859 (2013).

106. Schlüter, L., Lohbeck, K. T., Gröger, J. P., Riebesell, U. \& Reusch, T. B. H. Long-term dynamics of adaptive evolution in a globally important phytoplankton species to ocean acidification. Sci. Adv. 2, e1501660-e1501660 (2016).

107. Schlüter, L. et al. Adaptation of a globally important coccolithophore to ocean warming and acidification. Nat. Clim. Chang. 4, 1024-1030 (2014).

108. Aranguren-Gassis, M., Kremer, C. T., Klausmeier, C. A. \& Litchman, E. Nitrogen limitation inhibits marine diatom adaptation to high temperatures. Ecol. Lett. 22, 1860 1869 (2019).

109. Dam, H. G. Evolutionary adaptation of marine zooplankton to global change. Ann. Rev. Mar. Sci. 5, 349-370 (2013). 
110. Hinder, S. L. et al. Multi-decadal range changes vs. thermal adaptation for north east Atlantic oceanic copepods in the face of climate change. Glob. Chang. Biol. 20, 140-146 (2014).

111. Antell, G. S., Fenton, I. S., Valdes, P. J. \& Saupe, E. E. Thermal niches of planktonic foraminifera are static throughout glacial-interglacial climate change. Proc. Natl. Acad. Sci. U. S. A. 118, 1-9 (2021).

112. Lonhart, S. I., Jeppesen, R., Beas-Luna, R., Crooks, J. A. \& Lorda, J. Shifts in the distribution and abundance of coastal marine species along the eastern Pacific Ocean during marine heatwaves from 2013 to 2018. Mar. Biodivers. Rec. 12, 1-15 (2019).

113. Pinsky, M. L., Selden, R. L. \& Kitchel, Z. J. Climate-Driven Shifts in Marine Species Ranges: Scaling from Organisms to Communities. Ann. Rev. Mar. Sci. 12, 153-179 (2020).

114. Thurman, L. L. et al. Persist in place or shift in space? Evaluating the adaptive capacity of species to climate change. Front. Ecol. Environ. 18, 520-528 (2020).

115. Gilman, S. E., Urban, M. C., Tewksbury, J., Gilchrist, G. W. \& Holt, R. D. A framework for community interactions under climate change. Trends Ecol. Evol. 25, 325-331 (2010).

116. Dutkiewicz, S., Boyd, P. W. \& Riebesell, U. Exploring biogeochemical and ecological redundancy in phytoplankton communities in the global ocean. Glob. Chang. Biol. 27, 1196-1213 (2021).

117. Bernhardt, J. R. \& Leslie, H. M. Resilience to Climate Change in Coastal Marine Ecosystems. Ann. Rev. Mar. Sci. 5, 371-392 (2013).

118. Grant, P. R. et al. Evolution caused by extreme events. Philos. Trans. R. Soc. B Biol. Sci. 372, 5-8 (2017).

119. Gonzalez, A. \& Loreau, M. The causes and consequences of compensatory dynamics in ecological communities. Annu. Rev. Ecol. Evol. Syst. 40, 393-414 (2009).

120. Vallina, S. M. \& Le Quéré, C. Stability of complex food webs: resilience, resistance and the average interaction strength. J. Theor. Biol. 272, 160-73 (2011).

121. Neutel, A. M. et al. Reconciling complexity with stability in naturally assembling food webs. Nature 449, 599-602 (2007).

122. Ives, A. R. \& Cardinale, B. J. Food-web interactions govern the resistance of communities after non-random extinctions. Nature 429, 174-177 (2004).

123. Nagelkerken, I., Goldenber, S. U., Ferreir, C. M., Ullah, H. \& Conne, S. D. Trophic pyramids reorganize when food web architecture fails to adjust to ocean change. Science (80-. ). 369, 829-832 (2020). 
124. Carpenter, S. R. et al. Cascading trophic interactions and lake productivity. Bioscience 35, 634-639 (1985).

125. Bideault, A. et al. Thermal mismatches in biological rates determine trophic control and biomass distribution under warming. Glob. Chang. Biol. 27, 257-269 (2021).

126. Dee, L. E., Okamtoto, D., Gårdmark, A., Montoya, J. M. \& Miller, S. J. Temperature variability alters the stability and thresholds for collapse of interacting species: Species Interactions Facing Variability. Philos. Trans. R. Soc. B Biol. Sci. 375, (2020).

127. Adjeroud, M. et al. Recovery of coral assemblages despite acute and recurrent disturbances on a South Central Pacific reef. Sci. Rep. 8, 1-8 (2018).

128. Hughes, T. P. et al. Ecological memory modifies the cumulative impact of recurrent climate extremes. Nat. Clim. Chang. 9, 40-43 (2019).

129. Boyd, P. W. et al. Biological responses to environmental heterogeneity under future ocean conditions. Glob. Chang. Biol. 22, 2633-2650 (2016).

130. Ainsworth, T. D., Hurd, C. L., Gates, R. D. \& Boyd, P. W. How do we overcome abrupt degradation of marine ecosystems and meet the challenge of heat waves and climate extremes? Glob. Chang. Biol. 26, 343-354 (2020).

131. Pörtner, H.-O. Oxygen- and capacity-limitation of thermal tolerance: a matrix for integrating climate-related stressor effects in marine ecosystems. J. Exp. Biol. 213, 881-93 (2010).

\section{Develops concept of how other stressors can interact with each other in marine ectotherms}

132. Deutsch, C., Ferrel, A., Seibel, B., Portner, H.-O. \& Huey, R. B. Climate change tightens a metabolic constraint on marine habitats. Science (80-. ). 348, 1132-1135 (2015).

133. Deutsch, C., Penn, J. L. \& Seibel, B. Metabolic trait diversity shapes marine biogeography. Nature 585, 557-562 (2020).

134. Kroeker, K. J. et al. Impacts of ocean acidification on marine organisms: quantifying sensitivities and interaction with warming. Glob. Chang. Biol. 19, 1884-1896 (2013).

135. Bertolini, C. \& Pastres, R. Tolerance landscapes can be used to predict species-specific responses to climate change beyond the marine heatwave concept: Using tolerance landscape models for an ecologically meaningful classification of extreme climate events. Estuar. Coast. Shelf Sci. 252, (2021).

136. Le Gland, G., Vallina, S. M., Smith, S. L. \& Cermeño, P. SPEAD 1.0 - Simulating Plankton Evolution with Adaptive Dynamics in a two-trait continuous fitness landscape applied to the Sargasso Sea. Geosci. Model Dev. 14, 1949-1985 (2021). 
137. Merico, A., Bruggeman, J. \& Wirtz, K. A trait-based approach for downscaling complexity in plankton ecosystem models. Ecol. Modell. 220, 3001-3010 (2009).

138. Walworth, N. G., Zakem, E. J., Dunne, J. P., Collins, S. \& Levine, N. M. Microbial evolutionary strategies in a dynamic ocean. Proc. Natl. Acad. Sci. U. S. A. 117, 5943-5948 (2020).

139. Toseland, a. et al. The impact of temperature on marine phytoplankton resource allocation and metabolism. Nat. Clim. Chang. 3, 979-984 (2013).

140. Collins, M. et al. Extremes, Abrupt Changes and Managing Risk. in IPCC Special Report on the Ocean and Cryosphere in a Changing Climate (eds. Pörtner, H.-O. et al.) nn (2021).

141. Hughes, T. P. et al. Global warming and recurrent mass bleaching of corals. Nature 543, 373-377 (2017).

142. Cheung, W. W. L., Reygondeau, G. \& Frölicher, T. L. Large benefits to marine fisheries of meeting the $1.5^{\circ} \mathrm{C}$ global warming target. Science (80-. ). 354, 1591-1594 (2016).

143. Rashid Sumaila, U. et al. Benefits of the Paris Agreement to ocean life, economies, and people. Sci. $A d v$. 5, 1-10 (2019).

144. Tilbrook, B. et al. An enhanced ocean acidification observing network: From people to technology to data synthesis and information exchange. Front. Mar. Sci. 6, 1-21 (2019).

145. Claustre, H., Johnson, K. S. \& Takeshita, Y. Observing the Global Ocean with Biogeochemical-Argo. Ann. Rev. Mar. Sci. 12, 23-48 (2020).

146. Chai, F. et al. Monitoring ocean biogeochemistry with autonomous platforms. Nat. Rev. Earth Environ. 1, 315-326 (2020).

147. Fennel, K. et al. Advancing marine biogeochemical and ecosystem reanalyses and forecasts as tools for monitoring and managing ecosystem health. Front. Mar. Sci. 6, 1-9 (2019).

148. Reichstein, M. et al. Deep learning and process understanding for data-driven Earth system science. Nature 566, 195-204 (2019).

149. Sen Gupta, A. et al. Drivers and impacts of the most extreme marine heatwaves events. Sci. Rep. 10, 1-15 (2020).

150. Holbrook, N. J. et al. Keeping pace with marine heatwaves. Nat. Rev. Earth Environ. 1, 482-493 (2020).

151. Boyd, P. \& Hutchins, D. Understanding the responses of ocean biota to a complex matrix of cumulative anthropogenic change. Mar. Ecol. Prog. Ser. 470, 125-135 (2012).

152. Thomas, M. K. et al. Temperature-nutrient interactions exacerbate sensitivity to warming 
in phytoplankton. Glob. Chang. Biol. 23, 3269-3280 (2017).

153. Clark, J. R., Daines, S. J., Lenton, T. M., Watson, A. J. \& Williams, H. T. P. Individualbased modelling of adaptation in marine microbial populations using genetically defined physiological parameters. Ecol. Modell. 222, 3823-3837 (2011).

154. Bruggeman, J. \& Kooijman, S. a. L. M. A biodiversity-inspired approach to aquatic ecosystem modeling. Limnol. Oceanogr. 52, 1533-1544 (2007).

155. Small-Lorenz, S. L., Culp, L. A., Ryder, T. B., Will, T. C. \& Marra, P. P. A blind spot in climate change vulnerability assessments. Nat. Clim. Chang. 3, 91-93 (2013).

156. Sala, E. et al. Protecting the global ocean for biodiversity, food and climate. Nature 592, 397-402 (2021).

157. Halpern, B. S. et al. An index to assess the health and benefits of the global ocean. Nature 488, 615-620 (2012).

158. Suryan, R. M. et al. Ecosystem response persists after a prolonged marine heatwave. Sci. Rep. 11, 1-17 (2021).

159. Costanza, R. et al. Changes in the global value of ecosystem services. Glob. Environ. Chang. 26, 152-158 (2014).

160. Liquete, C. et al. Current Status and Future Prospects for the Assessment of Marine and Coastal Ecosystem Services: A Systematic Review. PLoS One 8, (2013).

161. Glynn, P. W. \& D’Croz, L. Experimental evidence for high temperature stress as the cause of El Nino-coincident coral mortality. Coral Reefs 8, 181-191 (1990).

162. Eakin, C. M. et al. Caribbean Corals in Crisis: Record Thermal Stress, Bleaching, and Mortality in 2005. PLoS One 5, e13969 (2010).

163. Gardner, J., Manno, C., Bakker, D. C. E., Peck, V. L. \& Tarling, G. A. Southern Ocean pteropods at risk from ocean warming and acidification. Mar. Biol. 165, 1-12 (2018).

164. Banzon, V., Smith, T. M., Mike Chin, T., Liu, C. \& Hankins, W. A long-term record of blended satellite and in situ sea-surface temperature for climate monitoring, modeling and environmental studies. Earth Syst. Sci. Data 8, 165-176 (2016).

165. Shchepetkin, A. F. \& McWilliams, J. C. The regional oceanic modeling system (ROMS): a split-explicit, free-surface, topography-following-coordinate oceanic model. Ocean Model. 9, 347-404 (2005).

166. Moore, J. K., Doney, S. C., Kleypas, J. A., Glover, D. M. \& Fung, I. Y. An intermediate complexity marine ecosystem model for the global domain. Deep Sea Res. II 49, 403-462 (2002).

167. Dee, D. P. et al. The ERA-Interim reanalysis: configuration and performance of the data 
assimilation system. Q. J. R. Meteorol. Soc. 137, 553-597 (2011).

168. Good, S. et al. The current configuration of the OSTIA system for operational production of foundation sea surface temperature and ice concentration analyses. Remote Sens. 12, $1-$ 20 (2020). 


\section{SUPPLEMENTARY MATERIAL:}

\section{Simulations with the global GFDL Earth system model}

The global extreme event analysis was conducted with simulation results from the fully coupled Earth system model ESM2M developed at the Geophysical Fluid Dynamics Laboratory (GFDL) of the National Oceanic and Atmospheric Administration ${ }^{45}$. The atmosphere has a horizontal resolution of $2^{\circ}$ latitude $\times 2.5^{\circ}$ longitude and the ocean has a nominal horizontal resolution of $1^{\circ}$ latitude and $1^{\circ}$ longitude, increasing toward the Equator to up to $0.3^{\circ}$. Ocean biogeochemistry is simulated by the Tracers Of Phytoplankton with Allometric Zooplankton version 2.0 (TOPAZ2). It represents 30 prognostic tracers, includes three phytoplankton functional groups and implicitly simulated zooplankton activity. The GFDL ESM2M captures the observed large-scale biogeochemical patterns and variability. We use a 500-yr preindustrial control simulation with prescribed atmospheric $\mathrm{CO}_{2}$ concentrations at $286 \mathrm{ppm}$, as well as a historical simulation over the 1861-2005 period followed by a high (RCP8.5; RCP: Representative concentration pathway) simulation over the 2006-2100 period with prescribed atmospheric $\mathrm{CO}_{2}$ and non- $\mathrm{CO}_{2}$ greenhouse and natural forcing ${ }^{14}$. The RCP8.5 scenario is a high emission scenario without effective climate policies, leading to continued growth in greenhouse gas emissions.

We limit the evaluation of the global model to the assessment of simulating marine heatwaves (Figs. S1 \& S2). The fidelity of the model in simulating high acidity extremes ${ }^{14}$ and the mean state ${ }^{5,45}$ have been assessed elsewhere. We use NOAA's daily Optimum Interpolation SST (OISST) analysis product with a spatial resolution of $0.25^{\circ 164}$. This dataset provides a highquality global record of SST observations obtained from satellites, buoys, and Argo floats on a regular grid. Before doing the analysis, we regridded the OISST dataset to a regular $1^{\circ}$ grid to allow a direct comparison with the GFDL ESM2M model, which has a nominal horizontal ocean resolution of $1^{\circ}$. A marine heatwave is defined with a relative threshold of $99 \%$ using the OISST product from 1982 to 2019 as our baseline. Following this definition, marine heatwaves can be as short as one day, extend over only one grid cell and predominately occur in the warm season. Note that this definition differs from that used by ref $\left({ }^{9}\right)$ on the basis of the definition of $\operatorname{ref}\left({ }^{30}\right)$, leading to larger year-to-year variations compared to the results shown by $\operatorname{ref}\left({ }^{9}\right)$, since they consider heatwaves to occur any time during the year. This leads to a smoother distribution of heatwaves in time, and consequently a lesser degree of year-to-year variations.

The model simulates well the spatial pattern of maximum daily intensity of marine heatwaves with high intensity in the higher northern latitudes, the eastern equatorial Pacific and 
the northern part of the Southern Ocean (Fig. S1a,c). Lower intensities are simulated and observed in the subtropical gyres. Overall, the model simulates stronger differences in heatwave intensities between the different regions than seen in the observations. The modeled and observed durations differ more substantially, with the model overestimating the observed durations by about a factor of two to three (Fig. S1b,d). This is a well-known bias in CMIP-type of models (e.g. ${ }^{8,49}$ ). The observed pattern of the duration is only marginally captured by the model, although there is a general tendency in both model and observations for longer heatwaves in the higher latitudes and shorter heatwaves in the mid latitudes. A striking difference is the model's simulation of relatively long heatwaves in the tropics, a feature not seen in observations.

The GFDL ESM2M model captures very well the positive long-term trends in global mean SST (Fig. S2a) and annual number of marine heatwave days (Fig. S2b). Global SST is simulated to increase by $0.13^{\circ} \mathrm{C}$ decade $^{-1}$ from 1982 to 2019 . This is in very good agreement with the observed increase of $0.16^{\circ} \mathrm{C}$ decade $^{-1}$. Both the model and the observations indicate an increase in marine heatwave days per year of 1.3 days decade $^{-1}$ over the 1982-2019 period. Both maximum annual intensity and annual mean duration do not show any substantial trend over this period, whether in the GFDL ESM2M nor in the observational-based product. We do not expect that the model captures the phasing of the year-to-year variability in any of these metrics, as the fully coupled Earth system model simulates its own phasing of internal variability.

The very good agreement between modeled heatwave characteristic and the observational-based characteristics, apart from the duration, in addition to the model's high fidelity in simulating open ocean acidity extremes ${ }^{14}$ gives us great confidence in using this model for analyzing the mean state and trends in different characteristics of ocean biogeochemical extremes and heatwaves at the global scale. 

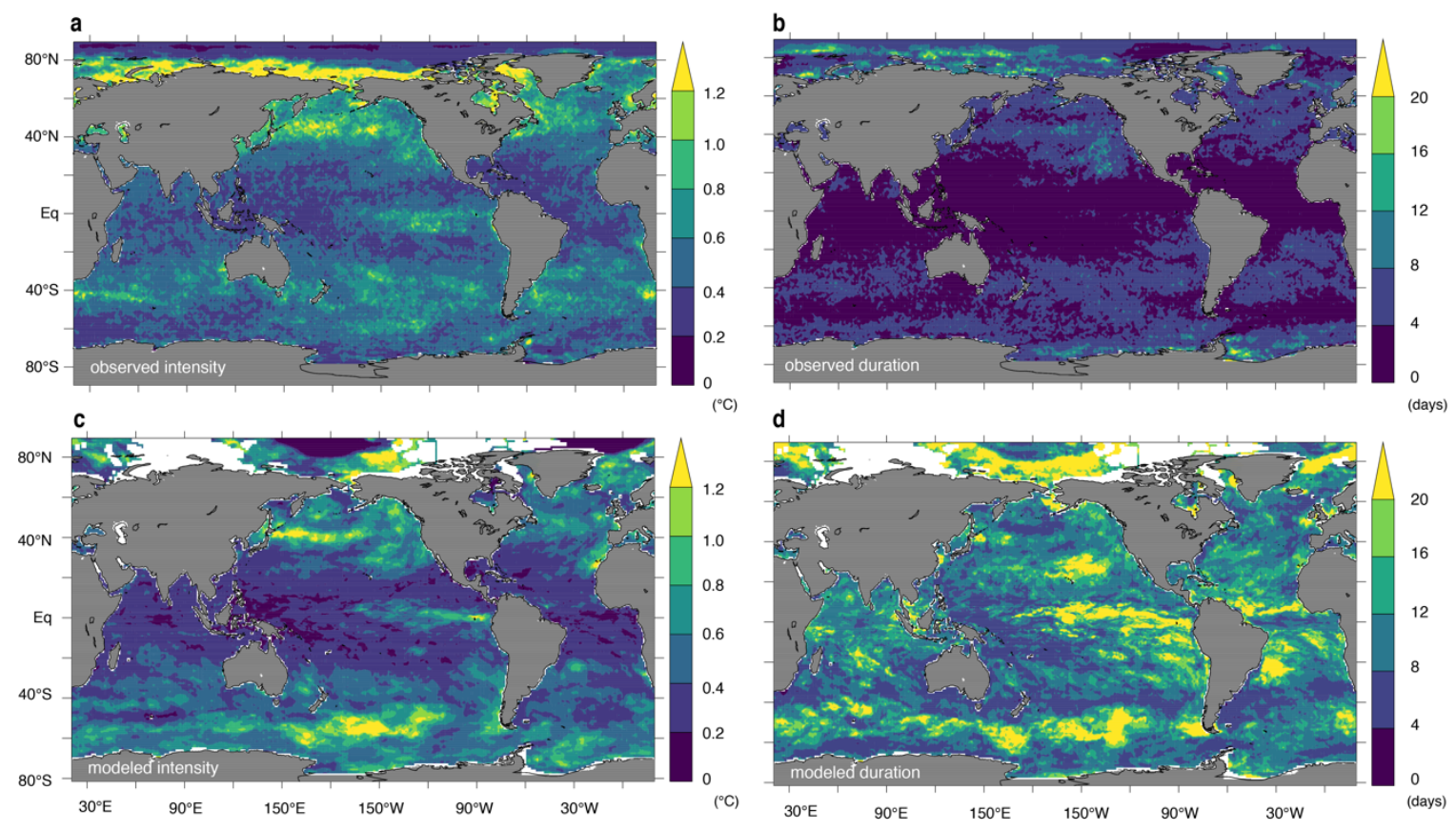

Supplementary Figure S1. Evaluation of the model simulated heatwave characteristics with observations. Shown are the results from the simulations with the GFDL ESM2M model ${ }^{45}$ and from the OISST product ${ }^{164}$. (a) and (b) are the observed maximum daily intensity $\left({ }^{\circ} \mathrm{C}\right)$ and average duration (days), respectively determined from the OISST product averaged over the period 1982 to 2019. (c) and (d) are the corresponding model simulated metrics from a combined historical (1982-2005) and RCP8.5 (2006-2019) simulation. 

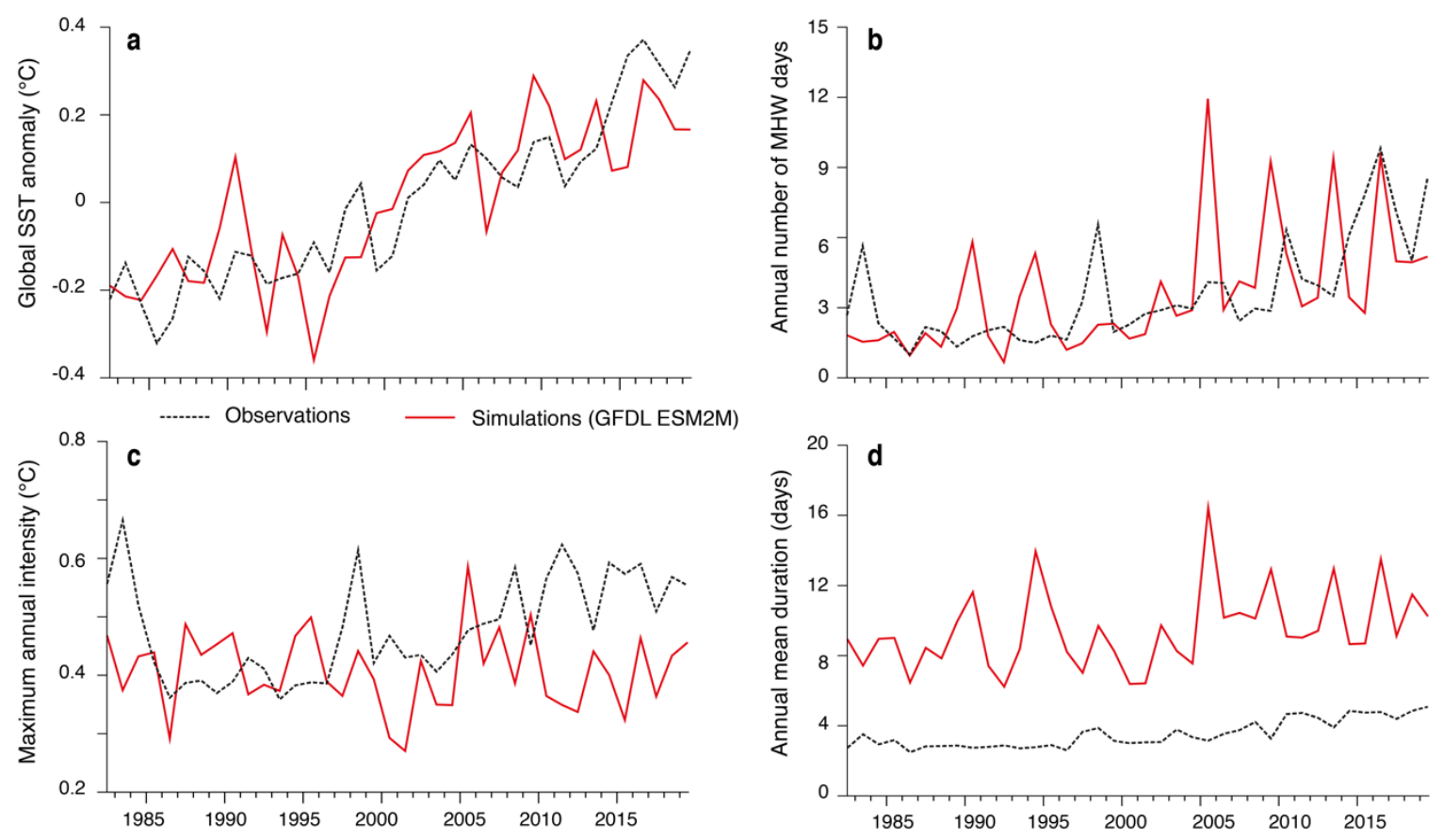

Supplementary Figure S2. Evaluation of the temporal dynamics of the model simulated heatwave characteristics in the global ocean. Shown are the results from the simulations with the GFDL ESM2M model ${ }^{45}$ (red line) and from the OISST product ${ }^{164}$ (black dashed line). (a) Timeseries of the global mean sea-surface temperature anomaly relative to the analysis period (1982 through 2019) $\left({ }^{\circ} \mathrm{C}\right)$. (b) Timeseries of the global mean annual number of marine heatwave days. (c) Timeseries of the maximum annual intensity $\left({ }^{\circ} \mathrm{C}\right)$. (d) Timeseries of the annual mean duration (days). 


\section{Simulations with the regional ROMS-BEC model}

The 2013-2015 "Blob" event was analyzed using hindcast simulations of the telescopic North Pacific setup of ROMS-BEC by ref $\left({ }^{69}\right)$. Briefly, the model system consists of the Regional Oceanic Modeling System (ROMS) ${ }^{165}$ coupled to an updated version of the Biogeochemical/Ecological Model (BEC) ${ }^{166}$. BEC explicitly resolves the cycling of four nutrient elements, which limit the growth of three phytoplankton functional groups, which are being kept under control by the grazing of a single zooplankton functional group. The model domain covers the entire Pacific, but has a strong resolution refinement toward the U.S. West Coast, with most of the area of interest having a resolution of 10 kilometers or better. The model was initialized from observations, and then run through the period 1970 to 2016 using daily fields of wind stress, solar short-wave radiation, and fluxes of heat and freshwater from ERA Interim ${ }^{167}$.

As was the case for the global model, we are limited in our evaluation to the assessment of the regional model's fidelity in simulating marine heatwaves (Figs. S3 \& S4) (For an evaluation of the mean state of the model, we refer to $\left.\operatorname{ref}\left({ }^{69}\right)\right)$. For the observations, we use here OSTIA SST product of the U.K. MetOffice ${ }^{168}$. This product is very similar to the OISST $^{164}$, with one of the differences constituting its focus on the foundation temperature, i.e., the temperature below the skin layer at the surface, which is a more suitable metric to compare to model results. As was done for the global model, we identified marine heatwaves using a relative threshold of $99 \%$ established from a daily climatology computed from daily data spanning the period January 1986 through December 2016 to establish our baseline. No additional requirements, such as minimum duration etc, were imposed. The comparison of the modeled marine heatwave intensities with the observed one reveals good agreement in magnitude and pattern, with a highly statistically significant pattern correlation of 0.49 across the entire analysis region $\left(20^{\circ} \mathrm{N}-60^{\circ} \mathrm{N}\right.$, $\left.155^{\circ} \mathrm{W}-115^{\circ} \mathrm{W}\right)($ Fig S3a,c). The model captures well the regions of more intense heatwaves along the northern U.S. west coast, extending southwestward into the open ocean, and a region of more intense heatwaves in around $45^{\circ} \mathrm{N}$ and $140^{\circ} \mathrm{W}$. Overall, the model exhibits slightly more contrast than the observations, leading to a slightly higher spatial standard deviation. The comparison is less favorable for the duration, where the modeled duration is nearly a factor of two longer than the observed one (Fig S3 b,d). At the same time, the pattern is similar, as evidenced by the positive spatial pattern correlation of 0.29 . Broadly speaking, regions with higher heatwave intensities also tend to have longer heatwaves, although this is not the case for the marine heatwaves along the U.S. West coast, which tend to be short lived. The factor of two difference in duration between our high-resolution regional model and the observations mimics the factor of nearly three difference seen in the global, coarser-resolution model (Fig. S1 b\&d, Fig. S2 d), 
suggesting that it cannot be resolution alone that creates this difference.

The hindcast simulation captures very well the spatial and temporal dynamics of the 2015 "Blob" heatwave event in the Northeast Pacific (Fig. S4). The model is able to track the evolution of the SST anomalies with substantial detail, such that the space-time evolution of the location and extent of the "Blob" heatwave event is reproduced with high fidelity (Fig. S4a-c). Still, there are some differences, largely at the edges of the identified patches where the SST conditions are extreme. But the spatial extent of the heatwave is very accurately captured. This is confirmed in Fig. S4d for the entire analysis period (1986-2016) with the modeled and observed spatial extent of the heatwaves in the analysis region being practically indistinguishable.

The excellent comparison of the modeled heatwave characteristics with the observed one for the regional high-resolution model gives us confidence that the model is sufficiently suited for analyzing the "Blob" event. Fundamental physical processes associated with the "Blob" heatwave must be well represented by the regional model, suggesting that this model is also doing reasonably well with its representation of the oxygen and acidity conditions during the "Blob". 

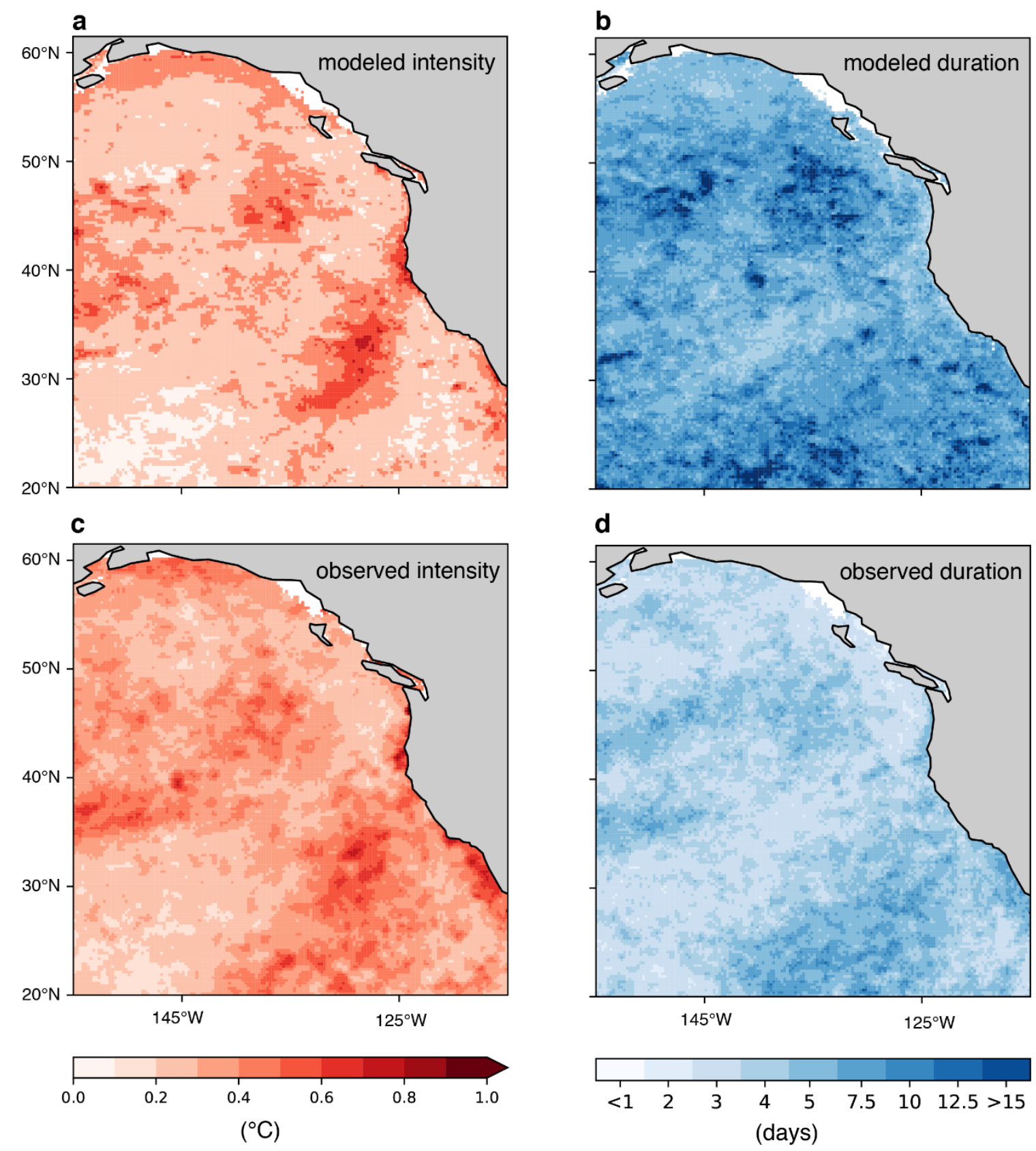

Supplementary Figure S3. Evaluation of model simulated heatwave characteristics in the

Northeast Pacific with observations. Shown are the results from the regional model simulations with ROMS-BEC for the period January1986 through December 2016 (a) for the average intensity $\left({ }^{\circ} \mathrm{C}\right)$, and (b) for the average duration of a heatwave. (c) and (d) show the corresponding metrics determined on the basis of the OSTIA sea-surface temperature product ${ }^{168}$. 

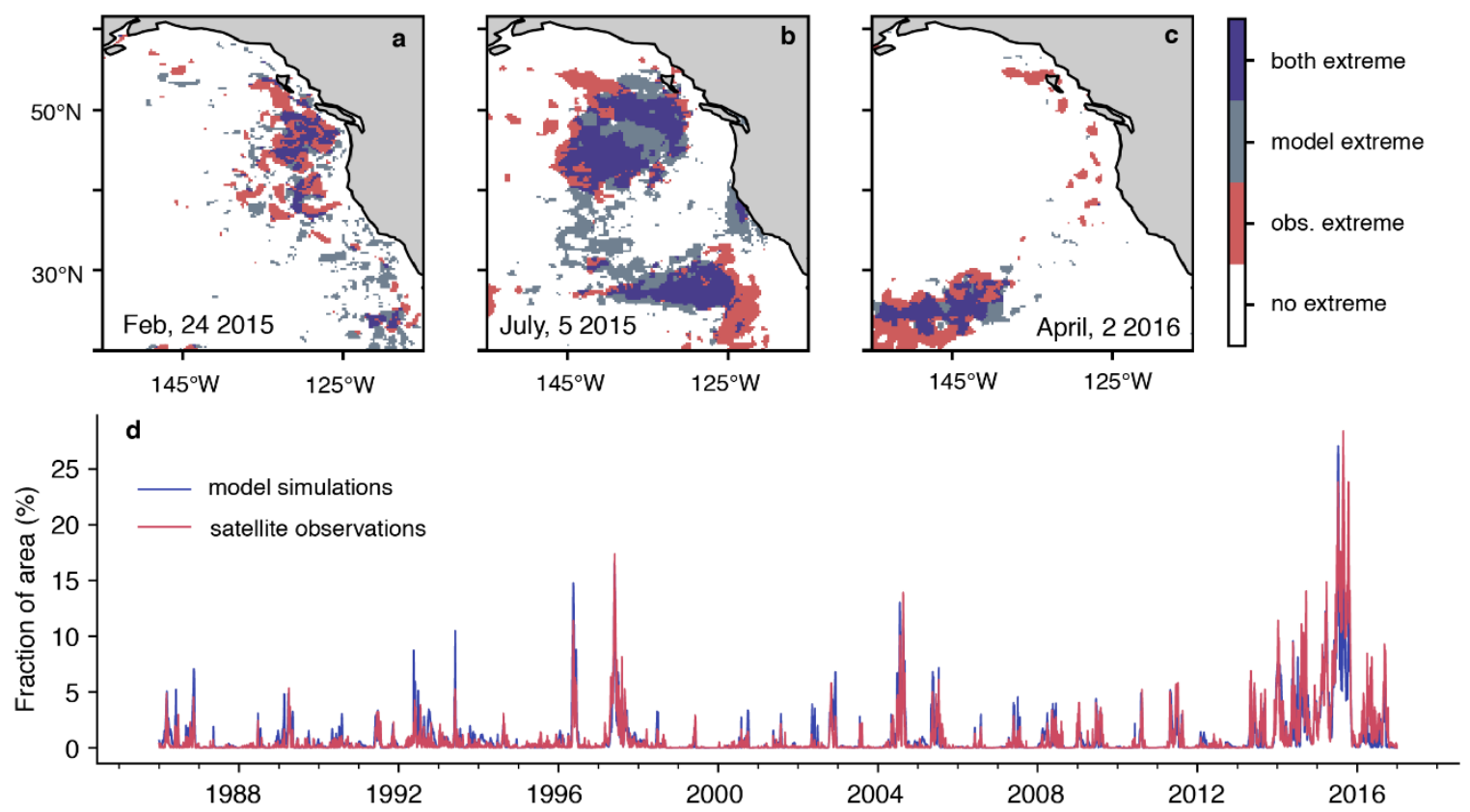

Supplementary Figure S4. Evaluation of the model simulated spatial and temporal

dynamics of marine heatwaves in the Northeast Pacific. $(a-c)$ Maps of the evolution of the spatial extent of the "Blob" marine heatwave as simulated by the model in comparison with observations. The blue color indicates the area where both the observations and the model indicate the presence of a marine heatwave. Areas where the colors are red depict areas where the observations indicate the presence of a heatwave, but not the model. For grey, the opposite is the case. Shown are three snapshots for (a) Feb 24, 2015, (b) July 5, 2015, and (c) April 2, 2016. (d) Timeseries of the area within the Northeast Pacific that is occupied by a marine heatwave for the model (blue) and for the observations (red). Shown are the results from the regional model simulations with ROMS-BEC and the OSTIA sea-surface temperature product ${ }^{168}$. 

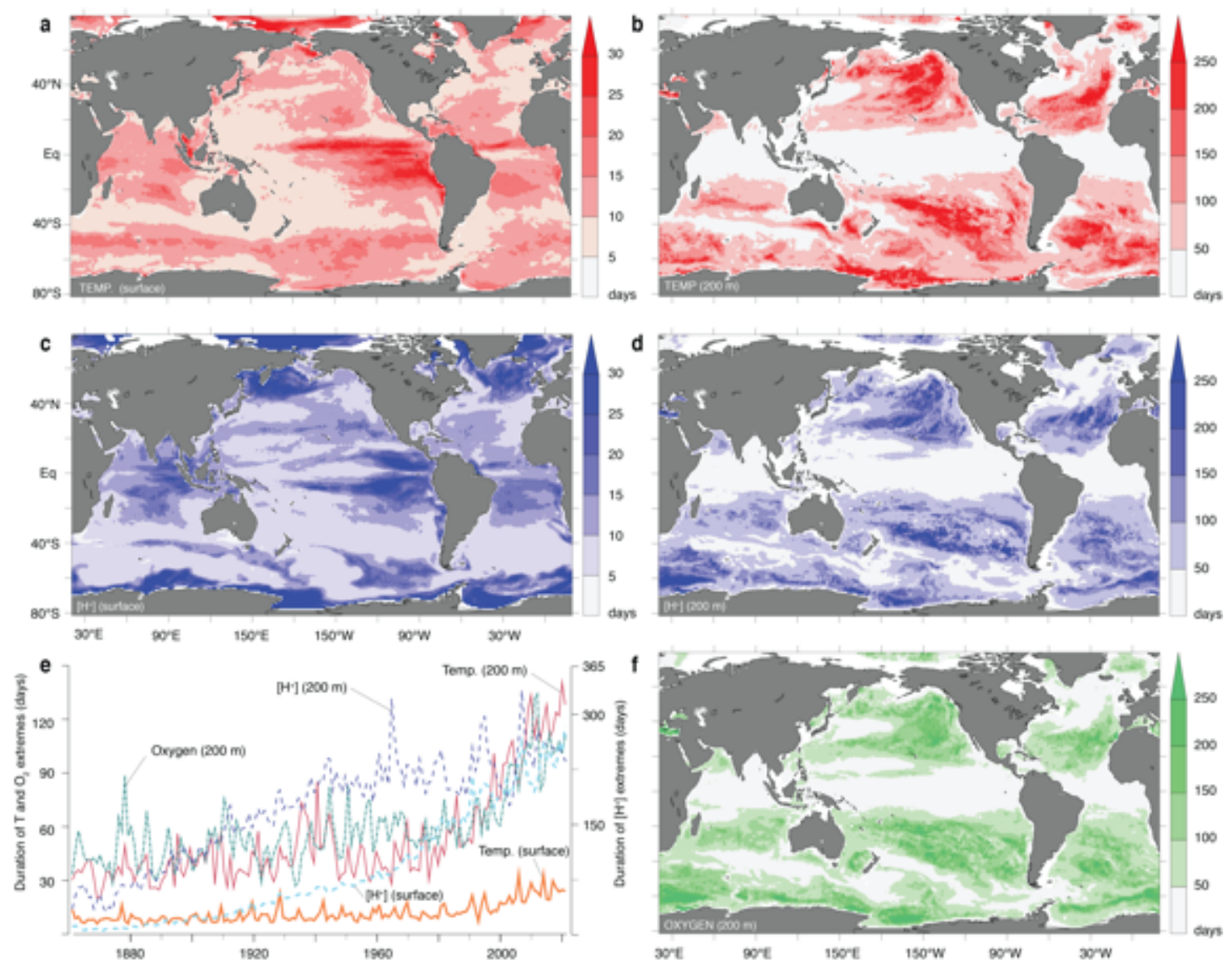

Supplementary Figure S5. Spatial distribution and temporal evolution of the duration of extreme events. (a-d \& f) Maps showing the average length of an extreme event during the preindustrial times. Marine heatwaves at (a) the surface and (b) at $200 \mathrm{~m}$ depth; High acidity extremes (c) at the surface and (d) at $200 \mathrm{~m}$ depth; (f) Low oxygen extremes at $200 \mathrm{~m}$ depth. (e) Timeseries showing the evolution of the global average duration of extreme events for the different types at the surface and at $200 \mathrm{~m}$ depth. All results are based on simulation results from the GFDL Earth System Model ${ }^{14}$. 


\section{Preindustrial versus modern reference period}

To assess the sensitivity of the results to our choice for the reference period, we recomputed the different metrics of the extremes for the global ocean using a modern reference period instead of the preindustrial reference period used in the text. Concretely, we used the model simulation results for the GFDL ESM2M model from the combined historical (1982-2005) and RCP8.5 (2006-2019) simulation to define the "modern" baseline and the thresholds. In order to take into consideration the strong trend in the $\left[\mathrm{H}^{+}\right]$over this period, we linearly detrended the data before computing the percentiles. We did the same for temperature and oxygen in order to be internally consistent, although the impact on the results for the latter two variables is relatively small. For $\left[\mathrm{H}^{+}\right]$, this makes a large difference, since the changes in $\left[\mathrm{H}^{+}\right]$over the nearly four decades is larger than the difference between the $10^{\text {th }}$ and the $90^{\text {th }}$ percentile.

Overall, the sensitivity of the key metrics of extremes with respect to the choice of the reference period is small (with the exception, of course, of the temporal evolution of these metrics). Supplementary Fig. S6 shows the results for the intensity at the surface and at $200 \mathrm{~m}$ depth for heatwaves, high acidity, and low oxygen extremes for both the modern reference period (top row) and the pre-industrial reference period (bottom row) (as shown in Fig. 2 in the main text). The pattern and magnitude of the intensities of all types of extremes are very similar between the two reference periods, but with the results from the modern reference period being spatiotemporally less coherent. This is primarily a consequence of the much shorter reference period (38 years versus 500 years), which leads to statistically much less well defined thresholds for the modern period. As a consequence of this statistical imprecision, the results get patchier.

The results for duration (not shown) are similar, with the pattern for the preindustrial reference period being very similar for all variables to that obtained for the modern period, except for the higher level of patchiness. The duration itself is very similar at the surface, but for all variables about $30 \%$ shorter at depth for the modern period. We attribute this difference also to the short reference period, which tends to skew the distribution toward the shorter events since the very long events are truly rare.

The low sensitivity of the results to the choice of the reference period is the result of a relatively stationary variability of temperature, $\mathrm{H}+$ and oxygen over the historical period. This means that the changes in the extremes seen in the timeseries are primarily driven by a shift in the mean of the distribution, rather than by changes in variance, especially for temperature and oxygen and to a lesser extent of $\mathrm{H}^{+}$. This also implies that the results shown here would also be representative for those obtained using a shifting baseline. 

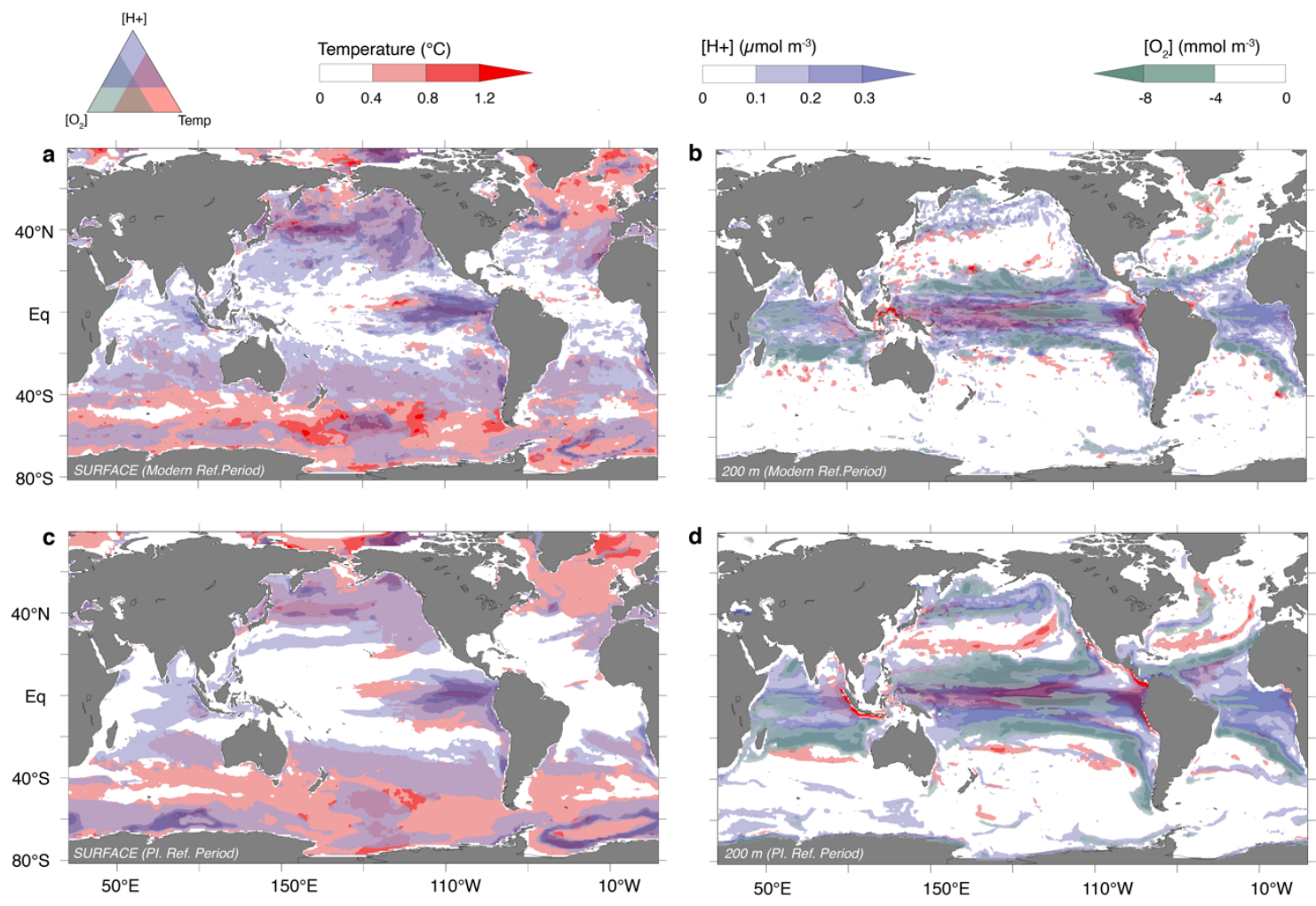

Supplementary Figure S6. Sensitivity of the intensity of extremes to the reference period: (a)

and (b) Mean intensities of all days when the thresholds are exceeded for heatwaves (red) $\left({ }^{\circ} \mathrm{C}\right)$,

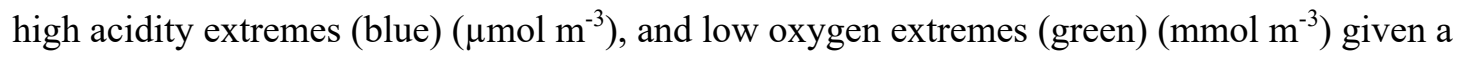
modern reference period (1982-2019). Shown are the intensities for (a) the surface layer, and (b) $200 \mathrm{~m}$ depth with the colors being mixed in regions of overlap. (c) and (d) as (a) and (b) but for the extremes having been defined relative to a 500-yr long pre-industrial reference period (see also Fig. 2). All results are based on simulation results from the GFDL Earth System Model ${ }^{14}$. 